$$
\begin{aligned}
& \text { كفاءة المؤشرات النباتيَّت } \\
& \text { في تقدير المحاميل الزراعية من مرئيات القمر المناعي } \\
& \text { لسبوت-0 في منطقة الهَدًا } \\
& \text { د. بسمة بنت سلامة الرحيلي }
\end{aligned}
$$


modeler, Operator, Classification, Overlay, تAccuracy assessment, Spatial analyst NDVI, توصلت الدراسة إلى انخفاض كفاءة مؤشرات IPVI, OSAVI, TSAVI2, WDRVI ومؤشرات EVI2, GEMI, TSAVI2 يِّ الفترة الرطبة، مِّْ تقدير تغطية النبات يِّ منطقة الدراسة، وعدم قدرتها على فصل انعكاس التربة عن انعكاس المحاصيل فيها. كما اتضح عند تمييز فئات كثافة المحاصيل الزراعية تفاوت

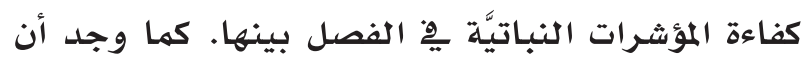
مؤشري MSAVI1, WDVI MSAVI1, OSAVI, WDVI

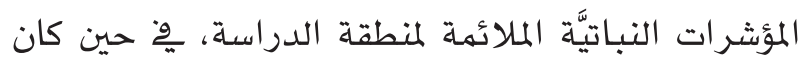
مؤشر MGNDVI أسوأ المؤشر ات النباتيَّة. كلمات مفتاحية: المؤشرات النباتيَّة الطيفية، التفطية

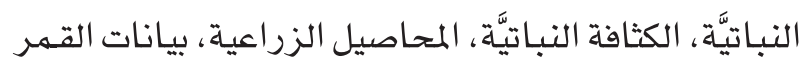

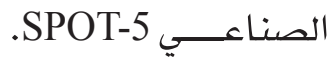

\section{|- مقدمة:}

تعد تقنية الاستشعار عن بعد الأسلوب الأمثل لرصد

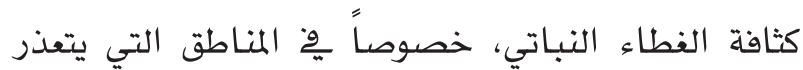
الوصول إليها بسهولة. وقد استخدمت المؤشرات النباتيَّة

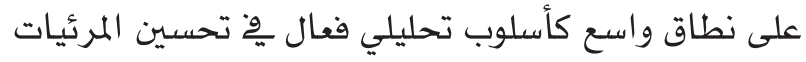

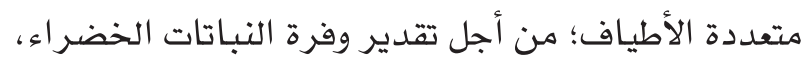

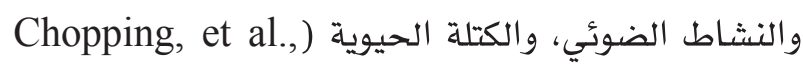

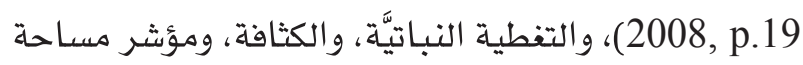

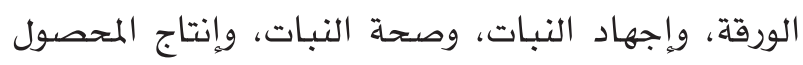
(Jackson and Huete, 1991, p.185) النباتيَّة بشكل كبير على الانعكاس الطيفي لاثنين أو أكثر من المن

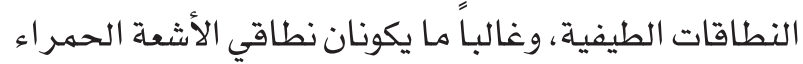
NIR (Ji and Peters, وتحت الحمراء القريبة Red

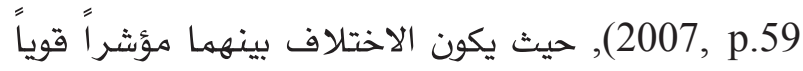

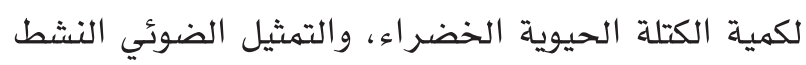
.(Teillet, et al., 1997, p.140) وقد أفاد استخد ام المؤشر ات النباتيَّة فِ التخفيف من تأثير

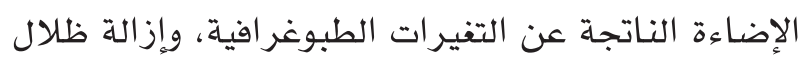

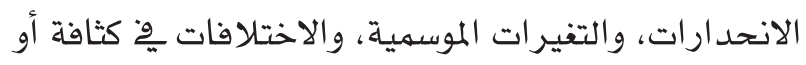
زاوية الشمس (Yang, et al., 2008, p.2) وِّ جميع مناطق واتق
كفاءة المؤشُرات النباتيَّت في تقدير المحاميل

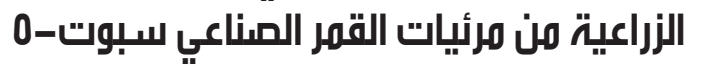

في منطقة الهَدَا

إعداد:

د. بسمة بنت سلامبة الرحيلي

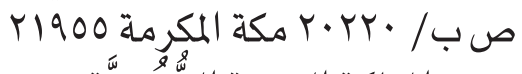
المملكة العربية السيّوديَّة

E-Mail: básma122008@gmail.com كفاءة المؤشرات النباتيَّة ِِِّ تقدير المحاصيل الزراعية من مرئيات القمر الصناعي سبوت-ه يِّ منطقة الهَهَا

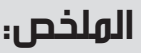

تعد بيانات الأقمار الصناعية وسيلة فعالة؛ لتمييز

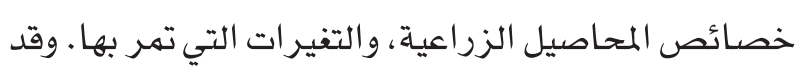
استخدمت المؤشرات النباتيَّة الطيفية Spectral vegetation indices (VIs)

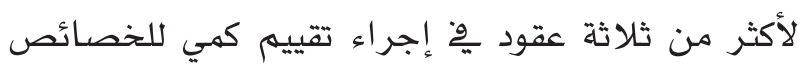

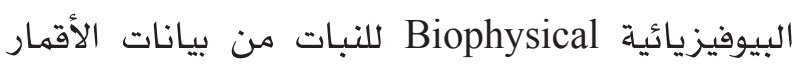

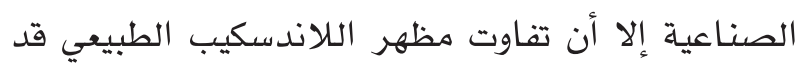

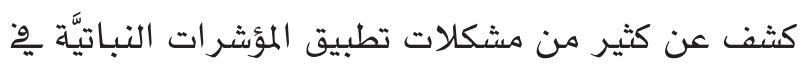

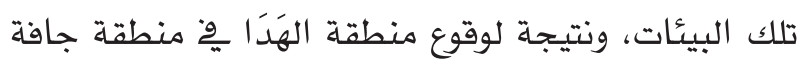

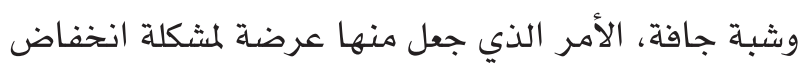

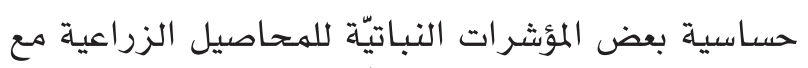

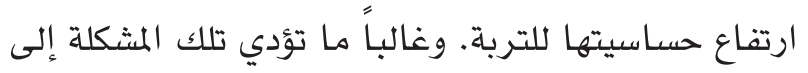

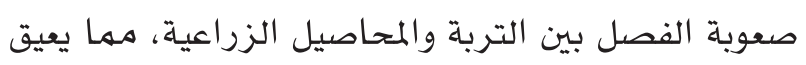

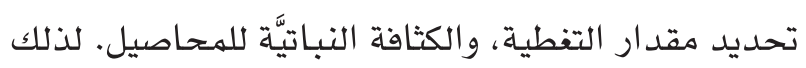
هدفت الدراسة إلى التعرف على كفاءة المؤشرات النباتيَّة

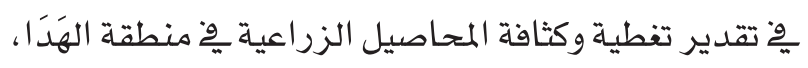

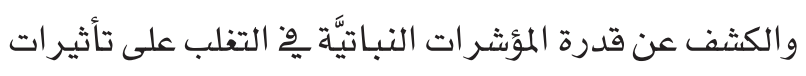

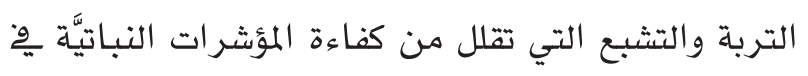

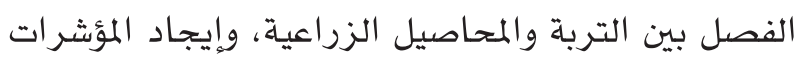
النباتيَّة الملائمة لتقدير المحاصيل الزراعية وِّو منطقة المَهَدَا،

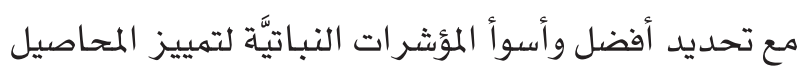
الزراعية، وفصل انعكاسها عن انعكاس التربة.

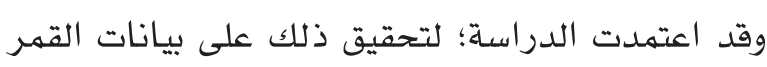

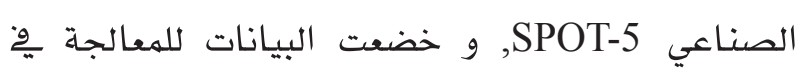
ERDAS IMAGINE9.1, Idrisi Taiga16.0, برامي Regress, Spatial بrcGIS9.2 باستخدام وظائف برائ 
تقدير المحاصيل الزراعية، بحيث تعطي قيهاً نباتيَّة عالية

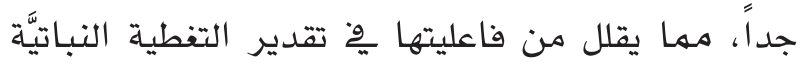

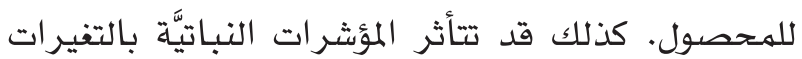

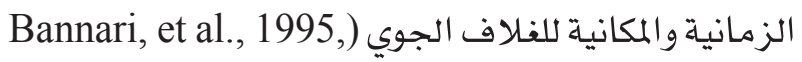

ونتيجة لتفاوت درجة كفاءة المؤشرات النباتيَّة بِّْ التفلب

على المؤثرات الخارجية برزت ضرورة ملحة لاختبارها، والتعرف على مدى كفاءتها بِّ تقدير ورصد خصائص

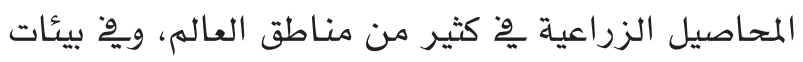

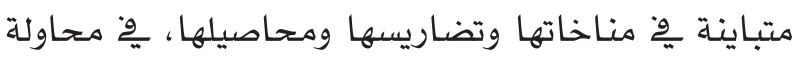

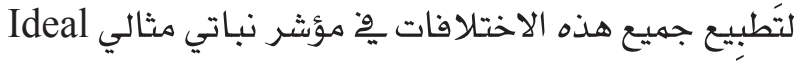
vegetation index عالية للمحاصيل الزراعية، وحساسية منخفضة للتربة، لا يتأثر بقدرة التمييز المكانية والطيفية للواقط الأقمار

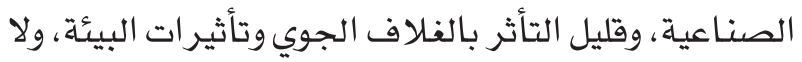

يتشبع بسرعة (Bannari and Asalhi, 2004). ونظراً لتهيز منطقة الهَدَا الواقعة ِِّْ شمال جبال

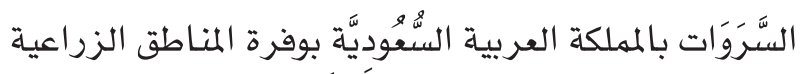

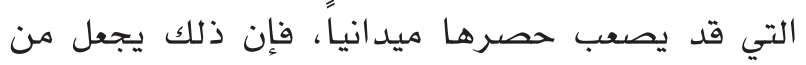

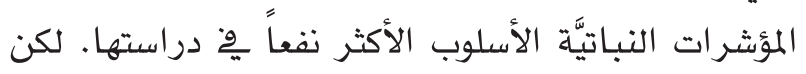

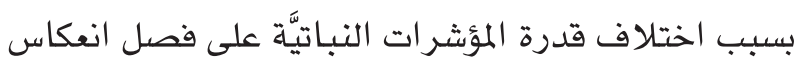

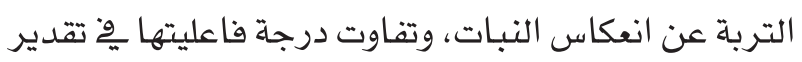
التفطية، والكثافة، كان لابد من معرفة فاعليتها يِّ تقدير تفطية وكثافة المحاصيل الزراعية يُّْ منطقة الهَدَا.

\section{「- مشكلة البحث:}

\section{يؤدي انخفاض التغطية النباتيَّة للهحاصيل ِِّ المناطق}

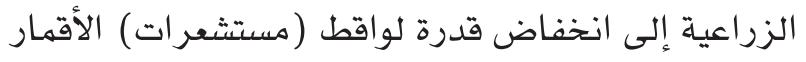

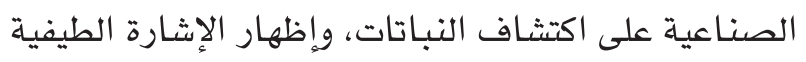

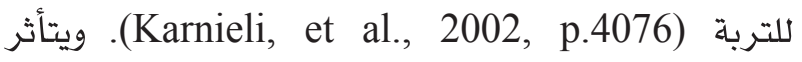
بذلك أداء المؤشرات النباتيَّة سلباً، إذ تصبح غير قادرة

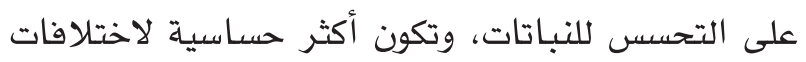

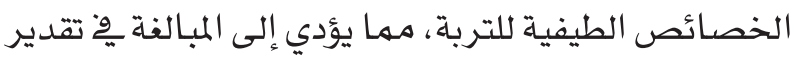

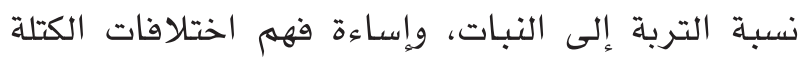

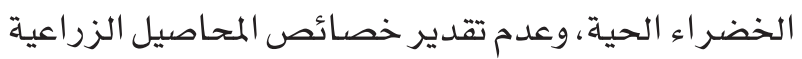

بشكل دقيق (Elvidge and Lyon, 1985, p.265). ونتيجة لتميز منطقة الهَدَا بكثرة الأراضي الزراعية التي (E) لتي
العالم باستثناء البيئات الجافة؛ بسبب الانعكاس العالي

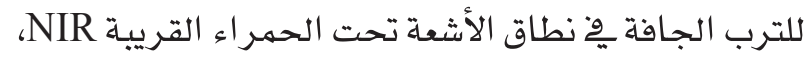

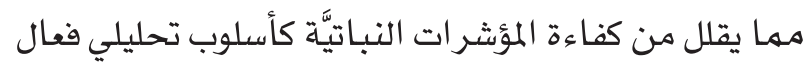

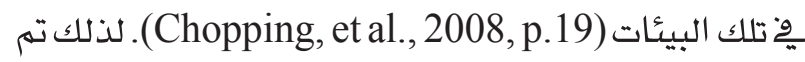

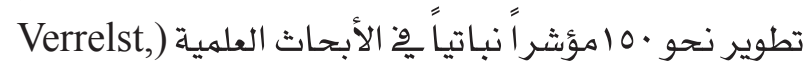

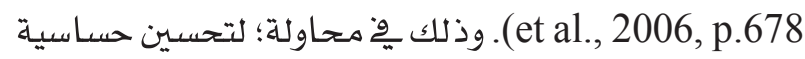

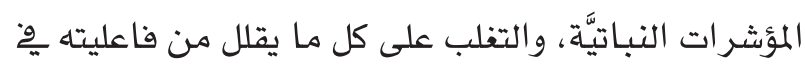

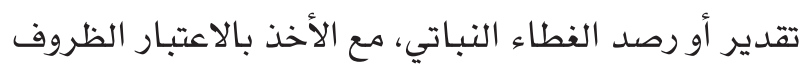

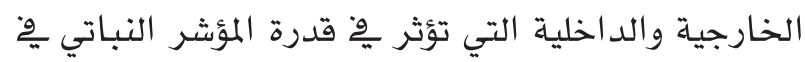
المنطقة المدروسة. وقد حظيت بعض الظروف الطبيعية

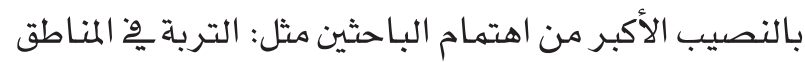

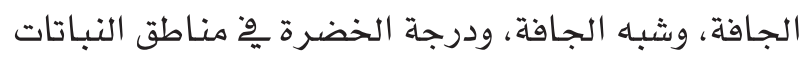

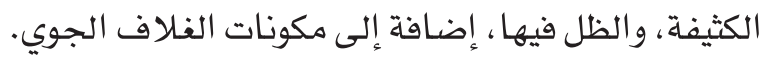

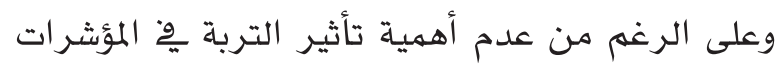

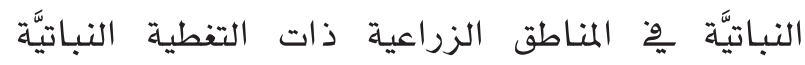
الكثيفة، فإن حدتها تبرز كلما قل مقدار التفطية النباتيَّة

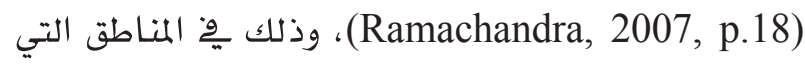
تسود فيها المحاصيل الزراعية قليلة الخضرة، والمبعثرة

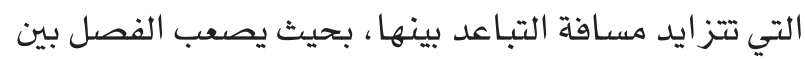

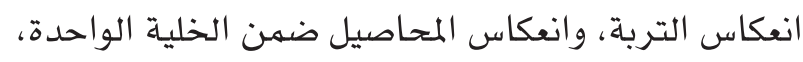

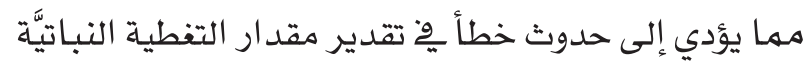

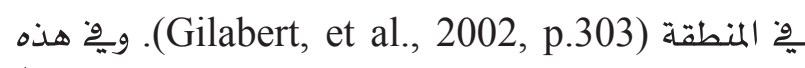
الحالة تعرض الاستجابة الطيفية للمناطق المزروعة خليطاً

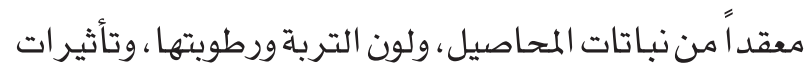

بئة الظلال (Bannari, et al., 1995, p.95). وعلى النقيض من مشكلة التربة تبرز مشكلة التشبع Saturation

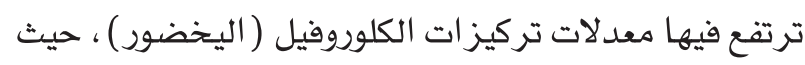
تبقى قيم المؤشر النباتي ثابتة مع زيادة كثافة تركية المحاصيل

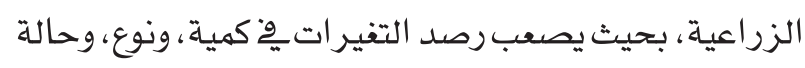

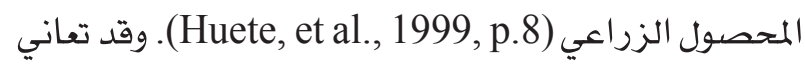
المؤشر ات النباتيَّة من مشكلة التشبع، ليس فقط بِّ المناطق

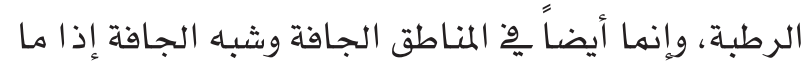

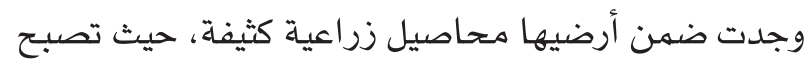

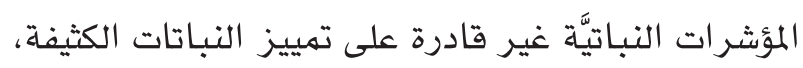
مها يؤثر بِّ فاعليتها بِّ تقدير كثافة المحاصيل الزراعية.

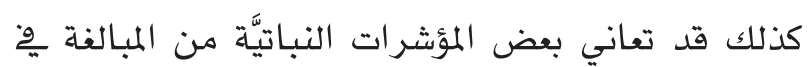


ج- التعرف على كفاءة المؤشر ات النباتئّة بِّ تقدير كثافة

المحاصيل الزراعية ِِّْ منطقة الهَدَا.

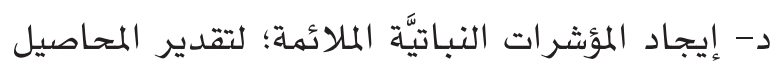

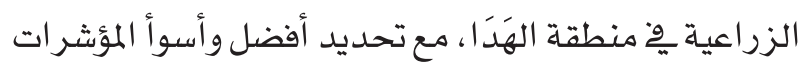

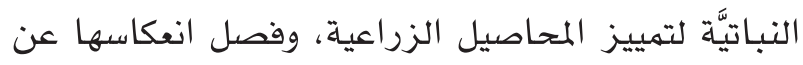

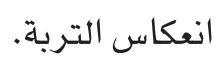

\section{ع- منطقة الدراستة:}

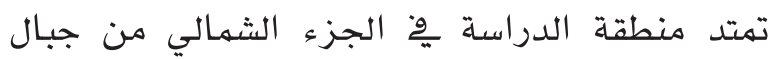

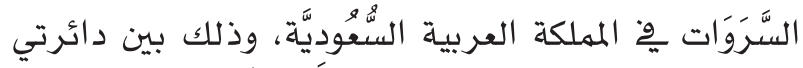

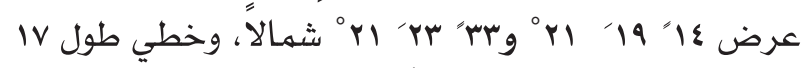

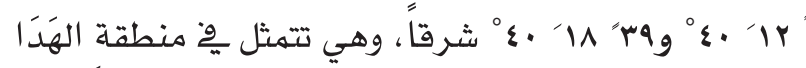

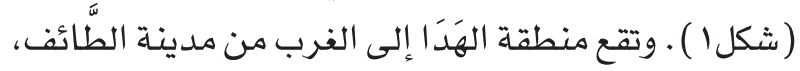

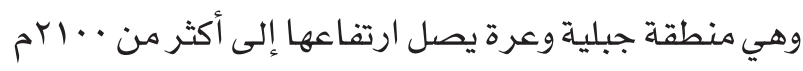
فوق مستوى سطح البحر، وتتمتع بوفرة غطائها النباتي

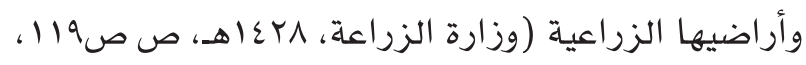

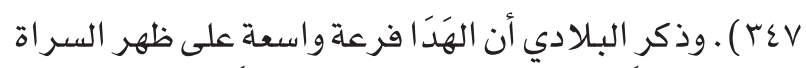

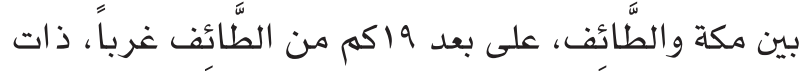

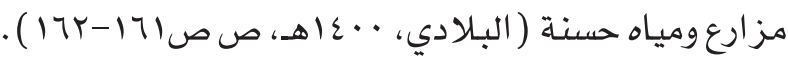

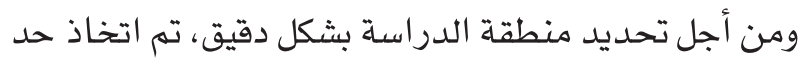

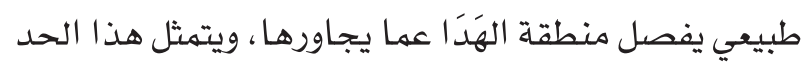

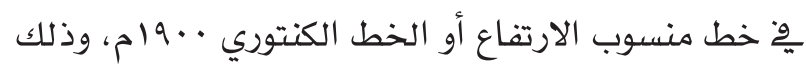

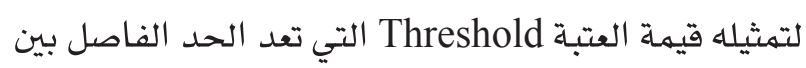

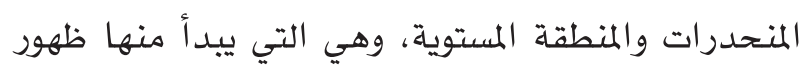
منطقة الهَهَا
تتفاوت محاصيلها من حيث التغطية، والكثافة، والتنوع بين

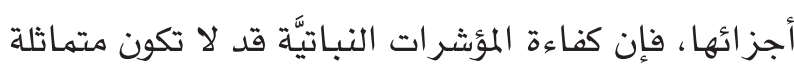

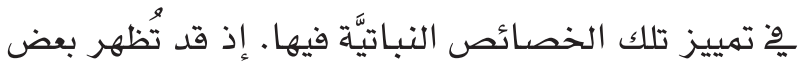

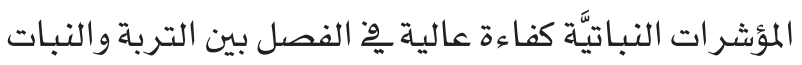

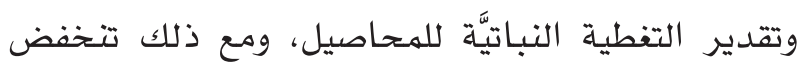

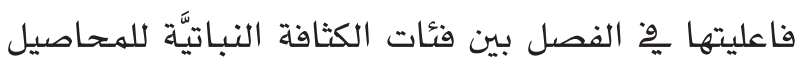

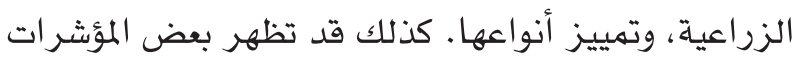

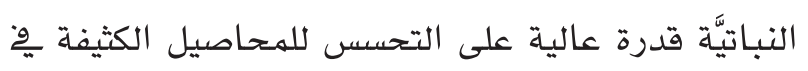

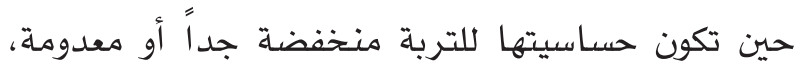

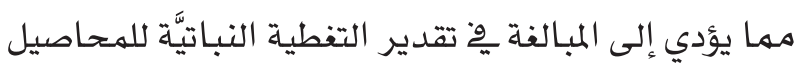

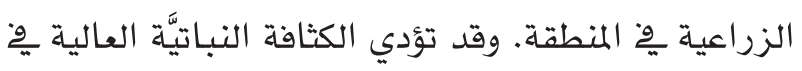

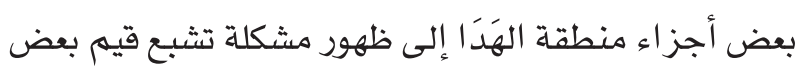

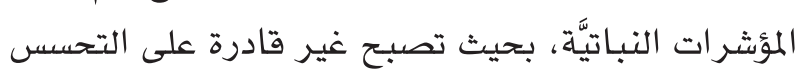

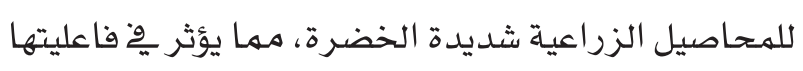

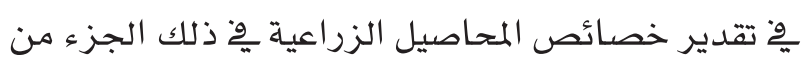
منطقة شمال جبال السَّرَوَات.

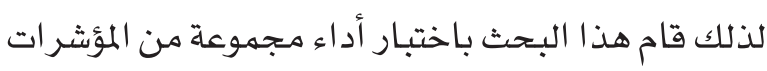

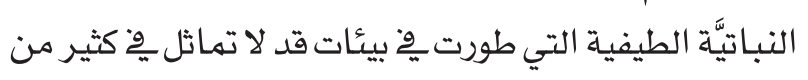

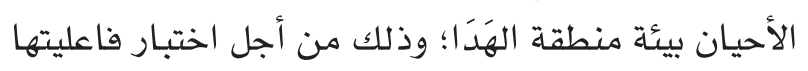

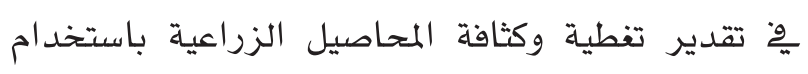

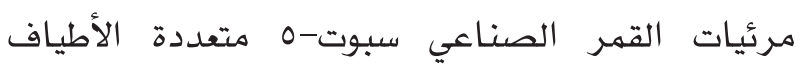

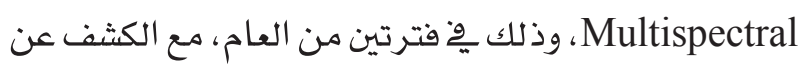

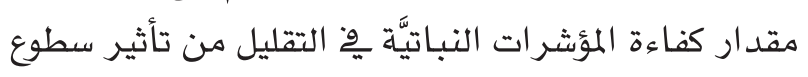

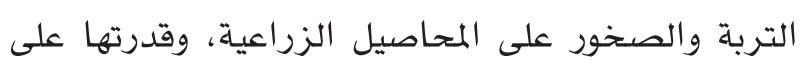

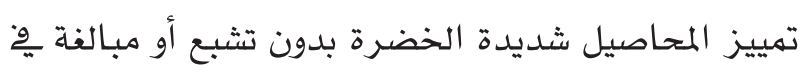

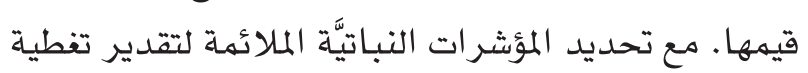
وكثافة المحاصيل الزراعية.

ש- أهداف البحث:

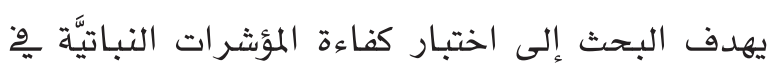

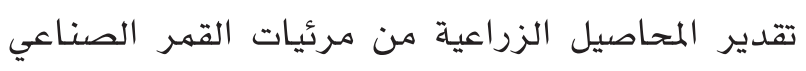

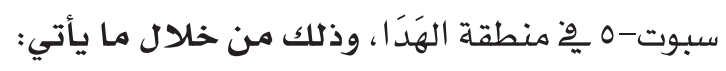

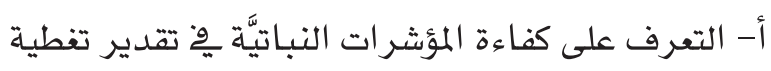

المحاصيل الزراعية ِِوْ منطقة الهَدَا.

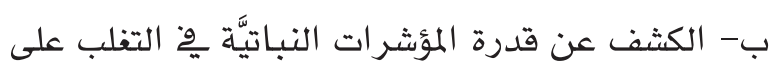

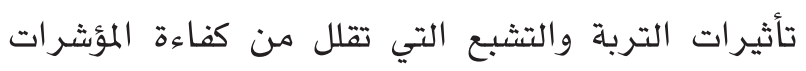

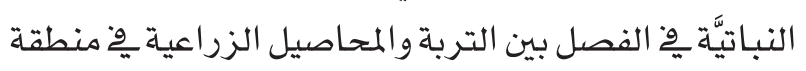




\section{شكل ( ) موقع منطقة الدراسة.}

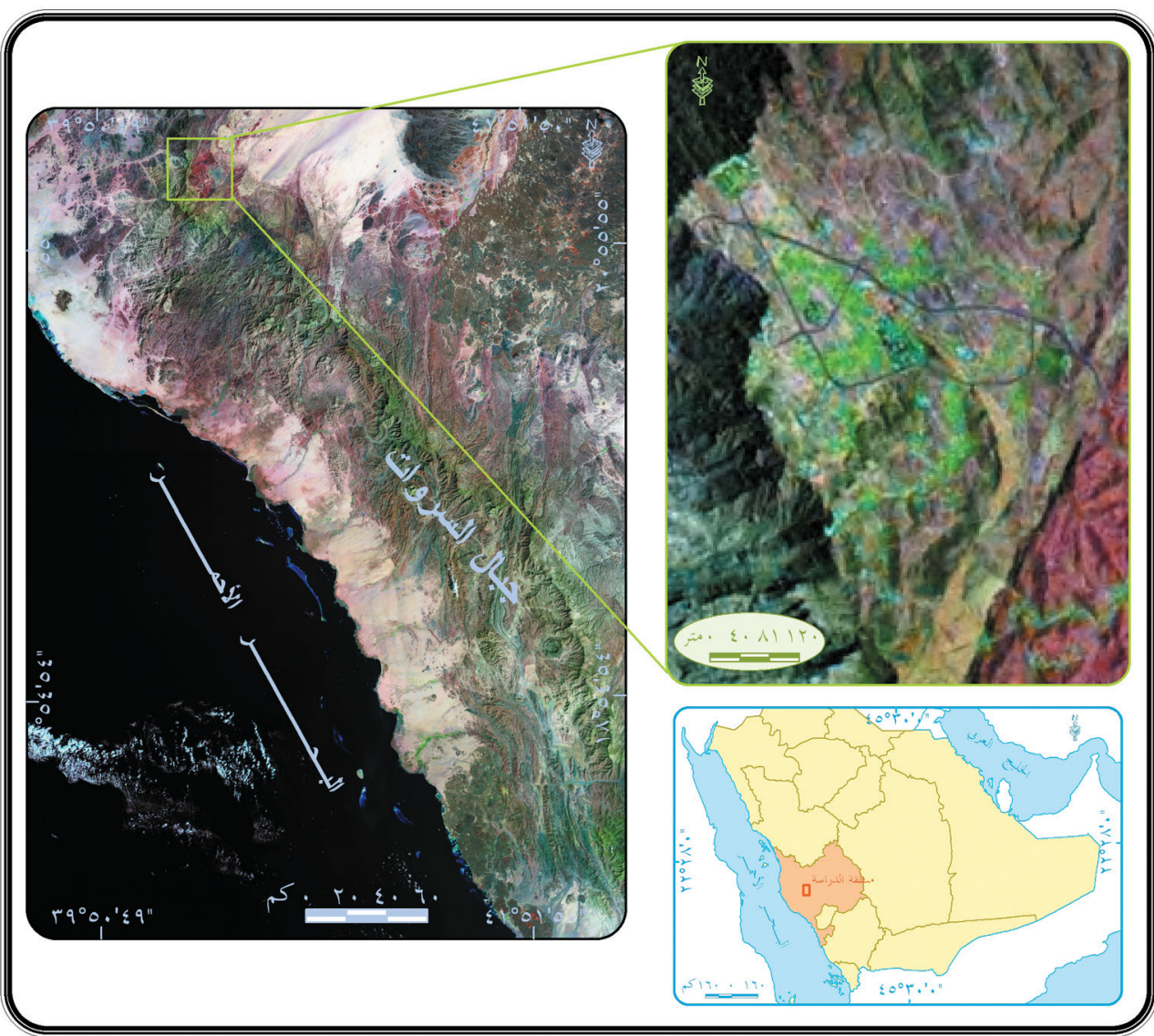

المصدر من عمل الباحثة اعتهاداً على: هيئة المساحة الجيولوجية السُُّوديَّة، ( •بعاهـة) ،

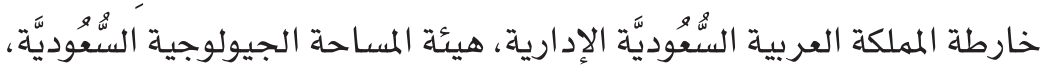

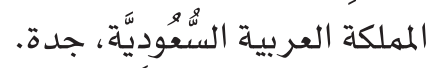

إسبانيا. وتوصلت الدراسة إلى أن مؤشر PRI كان أسوأ

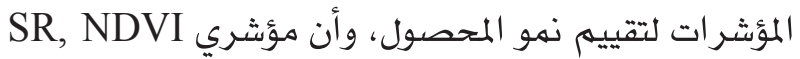
أفضل المؤشرات هوّ حساب مساحة المنطقة المزروعة.

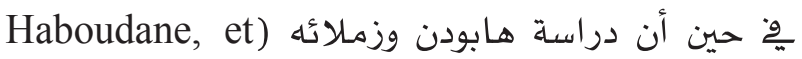

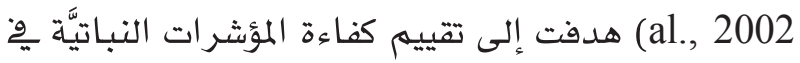
التنبؤ بهحتوى الكلوروفيل (اليخضور) لمحاصيل الذرة مون

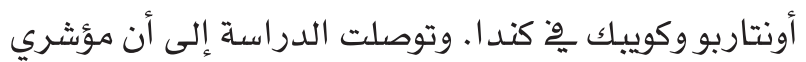
هCARI, OSAVI وِّ محتوى الكلوروفيل ولاختلافات LAI، وأن الجمع بينهما أدى إلى تحسين حساسيتهما للتغير ات ِّ2 محتوى الكلوروفيل

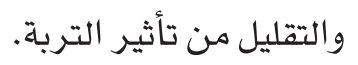

Kogan, et al.,) وقد هدفت دراسة كوغان وزملائهة

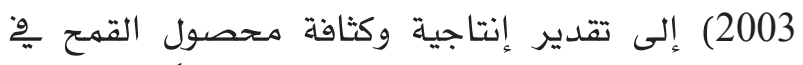

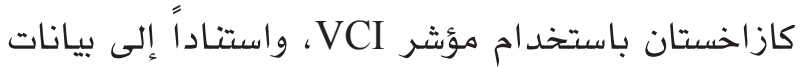
. AVHRR
كمنطقة مستوية، أو يبدأ عندها رأس الجال ( الكوستا) بوْ الظهور وذلك من الجهة الفربية للمنطقة. وبذلك تفطي

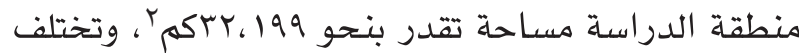

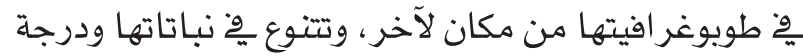
كثافتها ومحاصيلها الزراعية من جهة لأخرى.

\section{0- الدرالسات السـابقة:}

ظهرت دراسات عديدة اهتمت بتقييه أو اختبار كفاءة

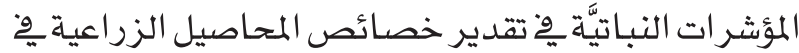
بيئات مختلفة؛ بهدف معرفة قدرتها ِِوْ التفلب على الظروف

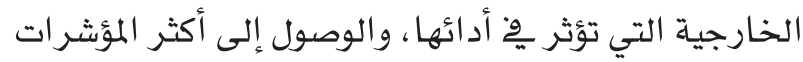

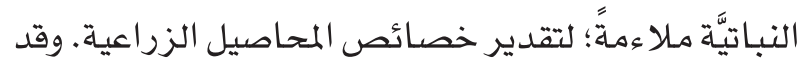

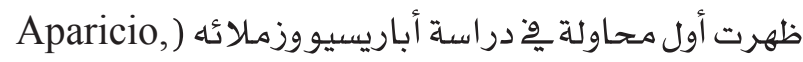

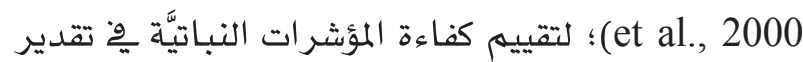
الخصائص الفسيولوجية لمحصول الحبوب شمال شرق 
هASVI2 هو أفضل مؤشر لتقدير LAI. سِّ حين أن دراسة زاو وزملائه (Zhao, et al., 2007) هدفت إلى مقارنة قدرة المؤشرات النباتيَّة؛ لتحديد النطاق الأمثل للمؤشرات

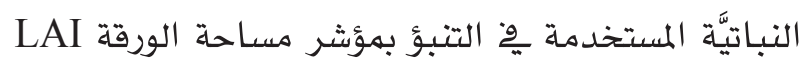

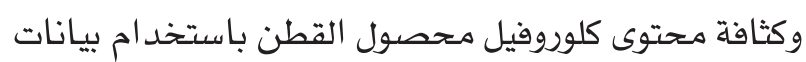

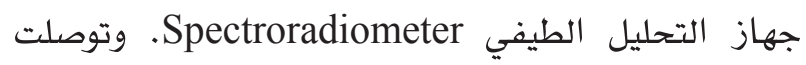

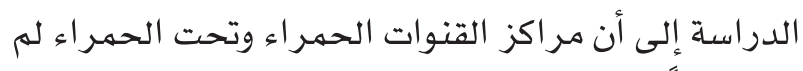

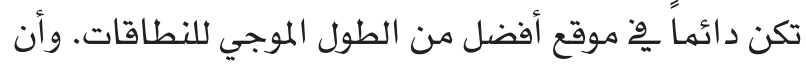

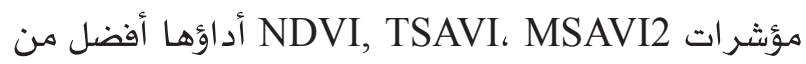

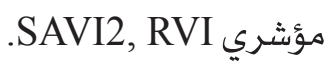

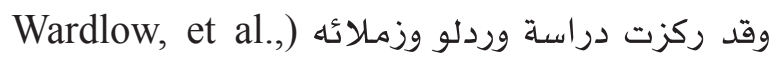

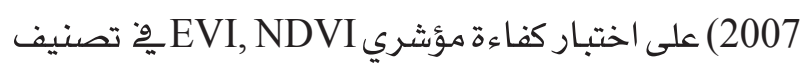
أنواع المحاصيل الزراعية بِّ2 السهول العظمى للولايات

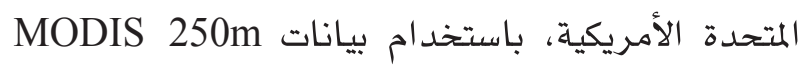

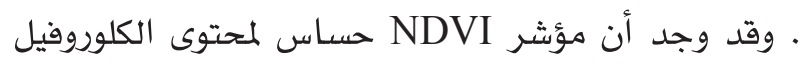

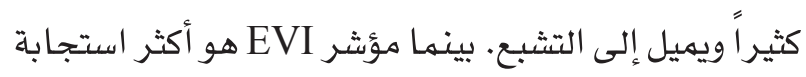

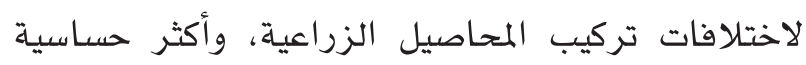

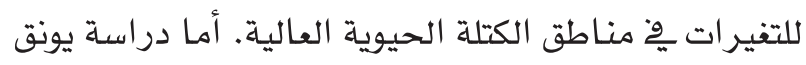
وزملائه (Yang, et al, 2008) فقد هدفت إلى اختبار

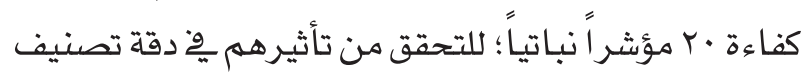

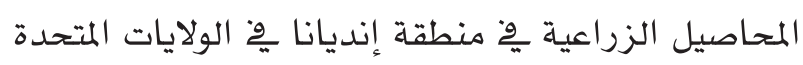
الأمريكية. وتوصلت إلى أن مؤشر RNDVI هو أفضل إنل

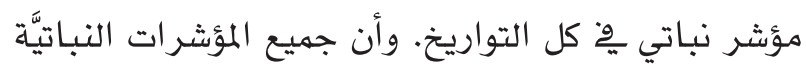
GRVI, المختارة أدت إلى دقة التصنيف باستثناء مؤشرات التوات وان OSAVI, MGRVI, SLAVI, NDMI عدم وجود دراسة واحدة اختصت بتقييم أو اختبار كفاءة

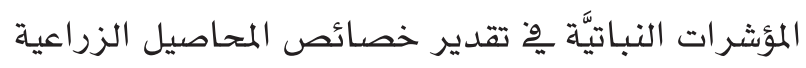

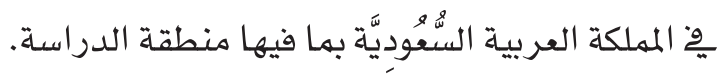

ר- منهم البحث:

تم التعرف على كفاءة المؤشرات النباتئّة ِِِّ تقدير

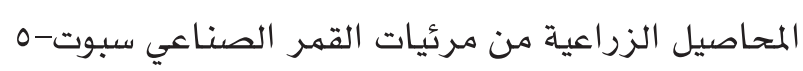

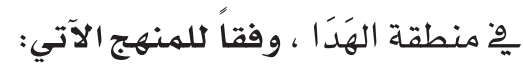
Selection of أ- اختيار المؤشرات النباتيَّة الطيفية الهين

:vegetation indices

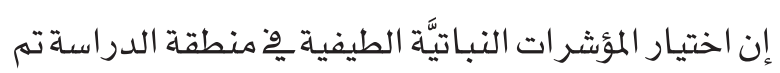

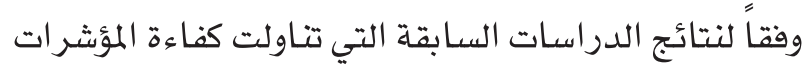

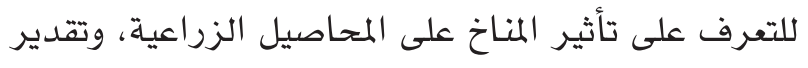

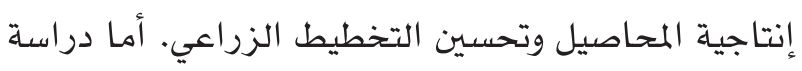

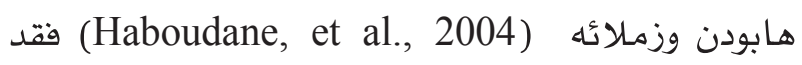

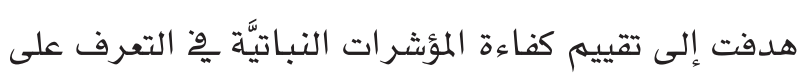

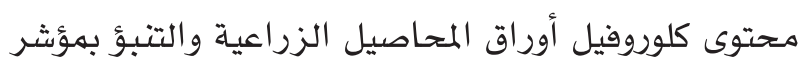

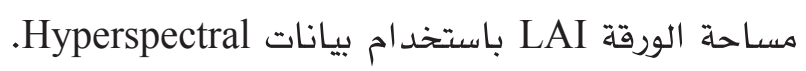
NDVI، RDVI,وتوصلت الدراسة إلى أن مؤشرات لئنسات SAVI, SARVI, MSAVI، TVI, MCARI, MTVI1، MCARI1، MTVI2، MCARI2

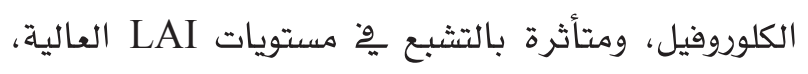
كما وجد أن مؤشري MTVI2، MCARI2 هما أفضل ومتاتئل المؤشرات. ولم يقتصر تقييم كفاءة المؤشرات النباتيَّة ِِوْ التنبؤ بهحتوى الكلورفيل وتقدير الإنتاج، وإنما شمل أيضاً فاعليتها

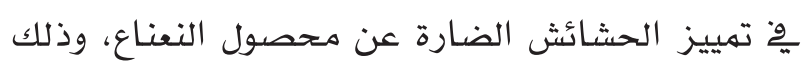

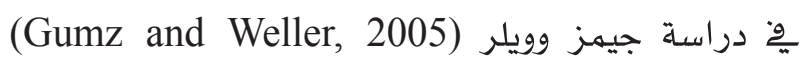
باستخدام جهاز راديوهتر طيفي. وتوصلت الدراسة إلى أن

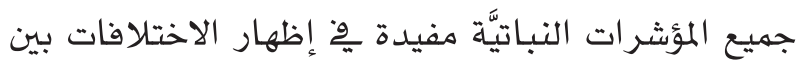

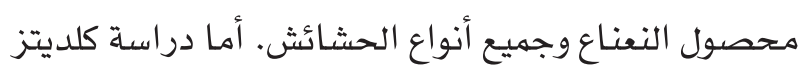

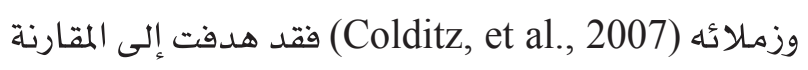
بين مؤشري EVI, NDVI يُّ تقدير الكتلة الحية الخضراء

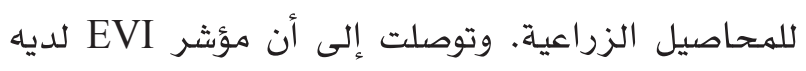

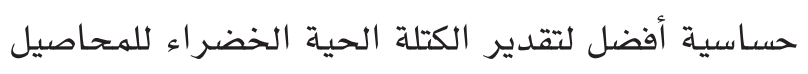

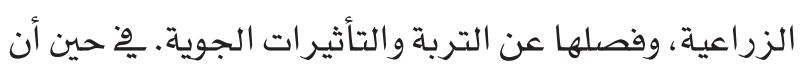

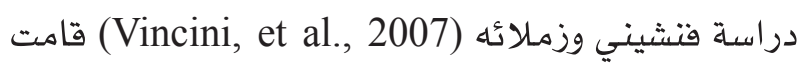

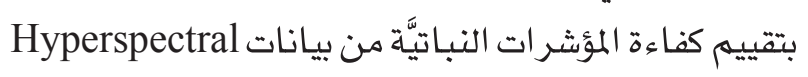
مِف تقدير كثافة مظلة محصول الذرة، وتوصلت إلى أن الن NDVI, DVI SR, MSR, RDVI, حساسية مؤشرات

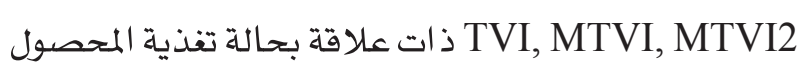
بالنيتروجين، إذ تتغير بتغير معدل الإخصاب، لذلك اقترح

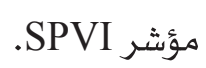

كذلك قامت دراسة وو وزملائه (Wu, et al., 2007) مؤن

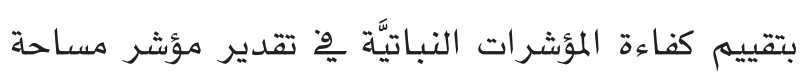
الورقة LAI لمحصول الذرة والبطاطا من بيانات كويك

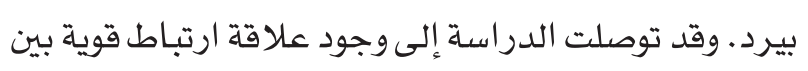

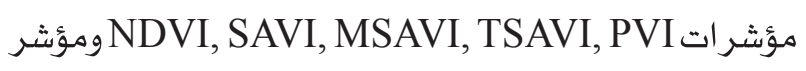
لكن بكفاءة مختلفة بين مؤشر وآخر . كما تبين أن مؤشر 
جدول ( ) معادلات المؤشر ات النباتيَّة.

$$
\begin{aligned}
& \text { النباتيَّة الطيفية وِّ2 تقدير خصائص المحاصيل الزراعية } \\
& \text { كالتنطية والكثافة والأنواعوالإنتاج الزراعي، وأكثرها شيوعاً }
\end{aligned}
$$

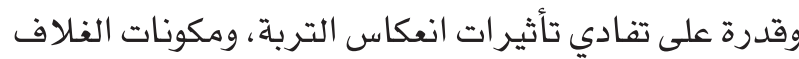

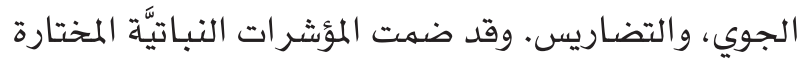

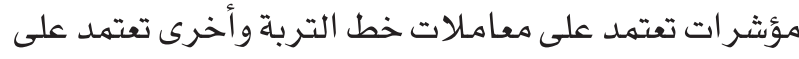

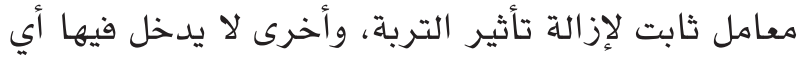

\begin{tabular}{|c|c|c|c|c|}
\hline Number & $\begin{array}{l}\text { Type } \\
\text { VI }\end{array}$ & Vegetation Index & Formula & $\begin{array}{l}\text { Source and } \\
\text { reference }\end{array}$ \\
\hline \multirow[t]{2}{*}{1} & \multirow{6}{*}{ 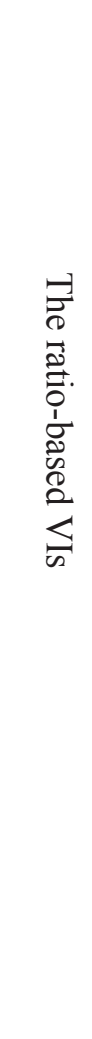 } & $\begin{array}{l}\text { Enhanced vegetation } \\
\text { index (EVI2). }\end{array}$ & $\begin{array}{c}\mathrm{EVI} 2=\mathrm{G} \times[(\mathrm{NIR}-\mathrm{Red}) /(\mathrm{NIR}+\beta \times \operatorname{Red}+\mathrm{L})] \\
\mathrm{G}=2.5, \quad \beta=2.4, \quad \mathrm{~L}=1\end{array}$ & Jiang, et al. 2008 \\
\hline & & $\begin{array}{l}\text { Global environment } \\
\text { monitoring index } \\
\text { (GEMI). }\end{array}$ & 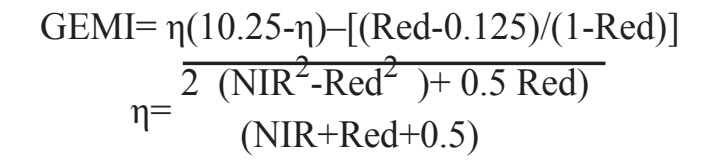 & $\begin{array}{c}\text { Pinty and } \\
\text { Verstraete, } 1992 .\end{array}$ \\
\hline 3 & & $\begin{array}{l}\text { Infrared Percentage } \\
\text { Vegetation Index } \\
\text { (IPVI). }\end{array}$ & IPVI $=[($ NIR-Red $) /($ NIR + Red $)]+1 / 2$ & Crippen, 1990. \\
\hline 4 & & $\begin{array}{l}\text { Mdified green } \\
\text { normalized difference } \\
\text { vegetation index } \\
\text { (MGNDVI). }\end{array}$ & MGNDVI=SWIR- Green/ SWIR + Green & $\begin{array}{l}\text { Gitelson, et al., } \\
1996 .\end{array}$ \\
\hline 5 & & $\begin{array}{l}\text { Normalized difference } \\
\text { vegetation index } \\
\text { (NDVI). }\end{array}$ & NDVI $=$ NIR - Red $/$ NIR + Red & $\begin{array}{l}\text { Rouse et al., } \\
1973 .\end{array}$ \\
\hline 6 & & $\begin{array}{l}\text { optimized soil- } \\
\text { adjusted vegetation } \\
\text { index (OSAVI). }\end{array}$ & OSAVI $=(\mathrm{NIR}-\mathrm{Red}) /(\mathrm{NIR}+\mathrm{Red}+0.16)$ & $\begin{array}{c}\text { Rondeaux, et al., } \\
1996 .\end{array}$ \\
\hline 7 & \multirow{4}{*}{ 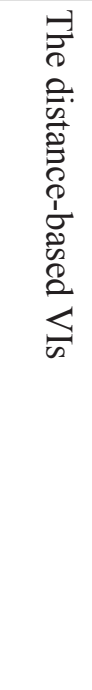 } & $\begin{array}{l}\text { Modified soil-adjusted } \\
\text { vegetation index } \\
\text { (MSAVI1). }\end{array}$ & $\begin{aligned} \text { MSAVI1 }= & {[(\mathrm{NIR}-\mathrm{Red}) /(\mathrm{NIR}+\mathrm{Red}+\mathrm{L})](1+\mathrm{L}) } \\
& \mathrm{L}=12-\mathrm{y} \text { NDVI } \times \text { WDVI }\end{aligned}$ & Qi, et al.,1994. \\
\hline 8 & & $\begin{array}{l}\text { Transformed soil- } \\
\text { adjusted vegetation } \\
\text { index (TSAVI2). }\end{array}$ & $\begin{array}{c}\text { TSAVI }=\mathrm{a}(\text { NIR }-\mathrm{a} \times \text { Red }-\mathrm{b}) /(\operatorname{Red}+\mathrm{a} \times \\
\left.\text { NIR }-\mathrm{a} \times \mathrm{b}+0.08\left(1+\mathrm{a}^{2}\right)\right) \\
\mathrm{a}=\text { slope }, \quad \mathrm{b}=\text { intercept. }\end{array}$ & $\begin{array}{c}\text { Baret and Guyot, } \\
1991 .\end{array}$ \\
\hline 9 & & $\begin{array}{l}\text { Wide dynamic range } \\
\text { vegetation index } \\
\text { (WDRVI). }\end{array}$ & $\begin{array}{c}\text { WDRVI }=(\mathrm{a} \times \text { NIR-Red }) /(\mathrm{a} \times \mathrm{NIR}+\mathrm{Red}) \\
\mathrm{a}=\text { slope. }\end{array}$ & Gitelson, 2004. \\
\hline 10 & & $\begin{array}{l}\text { Weighted difference } \\
\text { vegetation index } \\
\text { (WDVI). }\end{array}$ & $\begin{array}{c}\text { WDVI }=\text { NIR }- \text { Y Red } \\
y=\text { slope. }\end{array}$ & Clevers, 1989. \\
\hline
\end{tabular}

$$
\begin{aligned}
& \text { معامل لإزالة تأثير التربة، (جدولا الأير ). }
\end{aligned}
$$


خصائص المحاصيل الزراعية ِِّ منطقة الدراسة، بأخذ

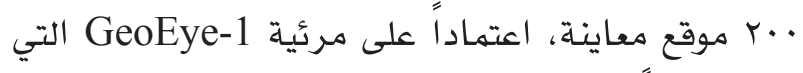

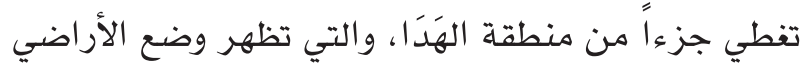

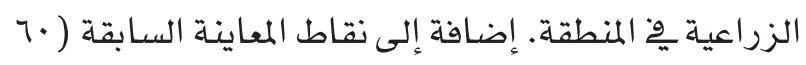

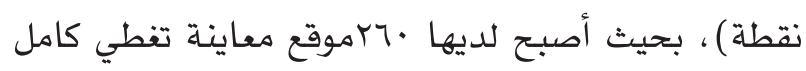

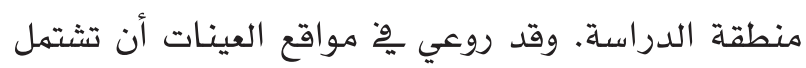

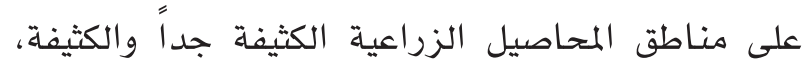

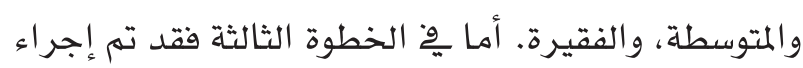

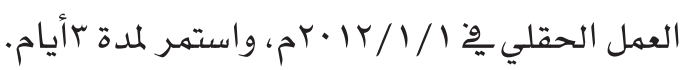
ج- معالجة البيانات:

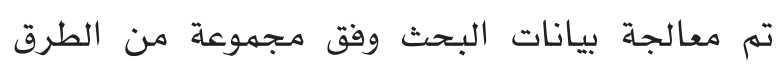
وأساليب التحليل والمعالجة، هي على النحو الآتي: Atmospheric تصحيح الغيلاف الجوي: 6S Model تم استخدام الأنموذج الرياضي:Correction إن الخطوات الآتية:

تحويل مرئيتا SPOT-5 من أعداد رقمية Digital number وذلك باستخدام المعادلة الآتية:

$$
p=\frac{D \_(c) \cdot \pi}{\left(G \cdot \cos (\theta s) \cdot E \_s\right)}
$$

حيث: Pي انعكاس أعلى طبقة من الغلاف الجوي TOA

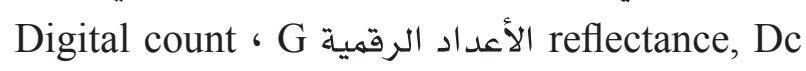

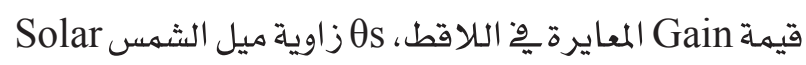
2.Solar radiation الإشعاع الشمسية zenith angle، ES الطول الموجي المناسب (Houlès, et al., 2006, p. 32). تطبيق الأنهوذج الرياضي 6S Model، ومعادلته كالآتي:

$$
\mathrm{acr}=\mathrm{y} \div(1+\mathrm{xc} \times \mathrm{y})
$$

حيث: y قيمة الانعكاس الطيفي للنطاق (ن)،

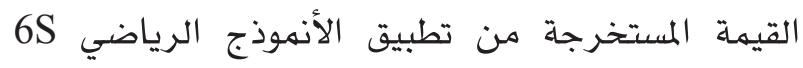
Model وقد تم بناء الأنموذج الرياضي ِِّ برنامج ERDAS

\section{.IMAGINE2011}

\section{- التصحيح الهندسي Geometric correction : تم التمأ}

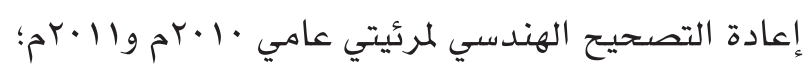
وذلك نتيجة لاختلاف التصحيح الهندسي للمرئيتين،

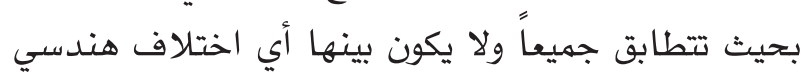

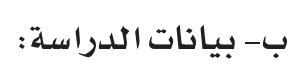 \\ تتمثل بيانات دراسة يف البيانات الأتية:}

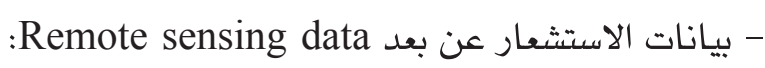
تم الاعتماد على بيانات الاستشعار عن بعد الأتية:

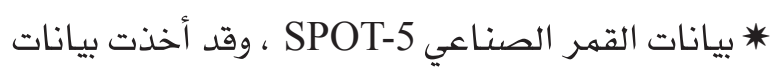

$$
\text { هذا اللاقط بِّ فترتين هما: }
$$

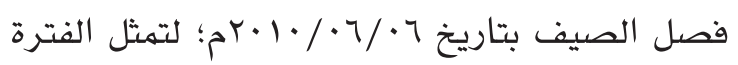

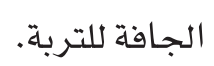

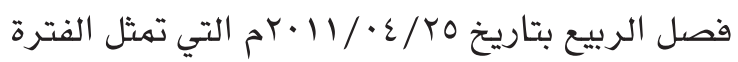

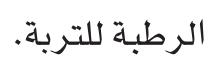

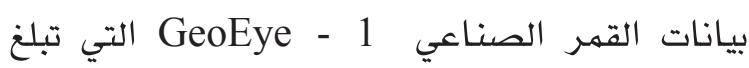
دقة تمييزها المكاني حوالي.7سهم وقد أخدت المبات بتاريخ

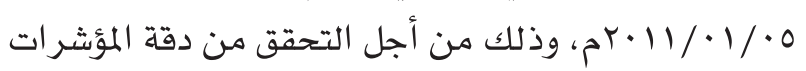

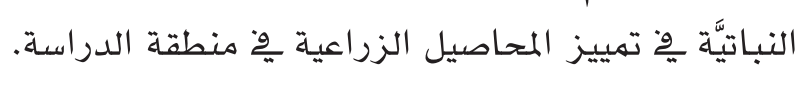

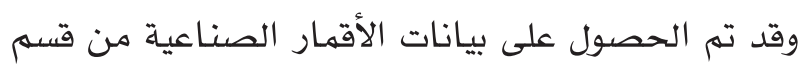

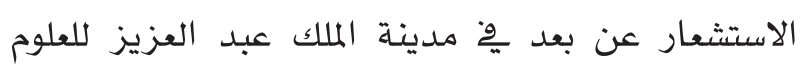
والتقنية وِ المملكة العربية السُّعوديَّة. - بيانات أنموذج الارتفاع الرقمي DEM:

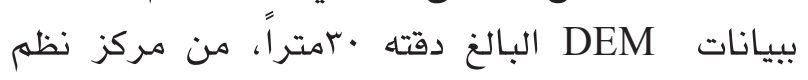

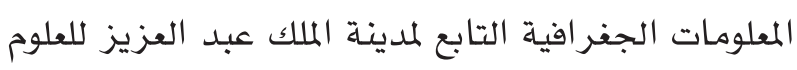
والتقنية ِِوْ المملكة العربية السُّعودِيَّة. - Field work العمل الحقلي

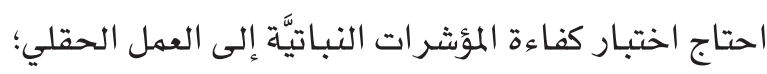

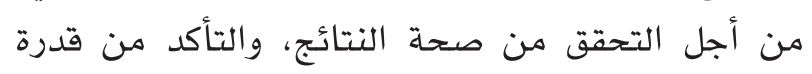

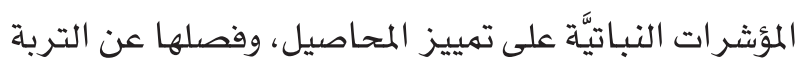

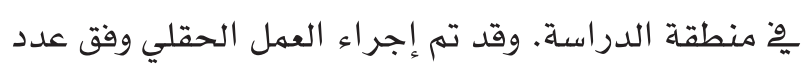

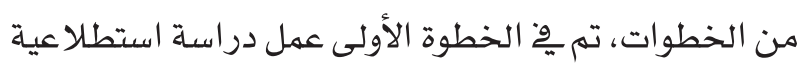

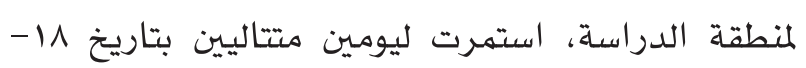

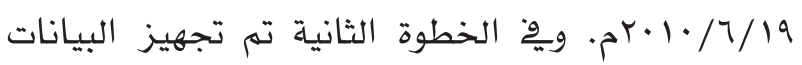

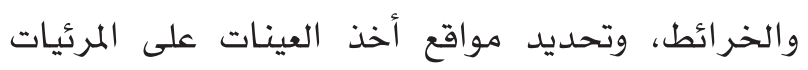

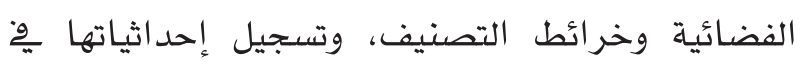

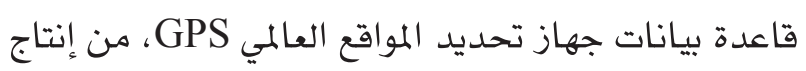
شركة GARMIN من نوع GPS • • قـ؛ من أجل الوصول إليها بسهولة يوّ الحقل. وقد أخدت العينات بالطريقة العمدية

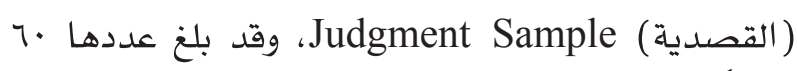

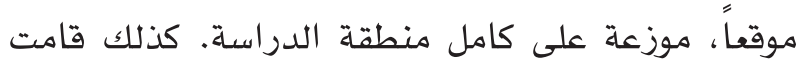

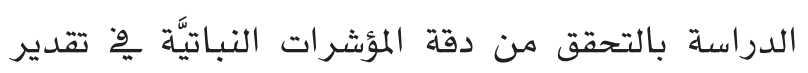


- بناء النماذج الرياضية للمؤشرات النباتيَّة: تم استخد ام وظيفة Spatial modeler ِِّ برنامج لبناء معادلات المؤشر ات النباتيَّة.

- تحديد قيمة العتبة Threshold: اختيرت قيمة العتبة الفعلية التي تصبح بعدها المؤشرات النباتيَّة غير التئة

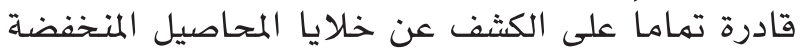
الكثافة، وذلك لكل مؤشر نباتي على حدة، باستخدام طريقة الانحر اف المعياري Standard deviation. وقد استخدمت

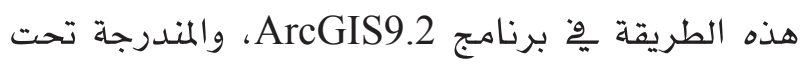
وظيفة Classification، حيث صنفت المنطقة إلى فئتين؛

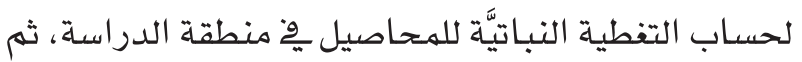
إلى ثلاث فئات؛ لحساب تغطية كثافة المحاصيل الزراعية؛

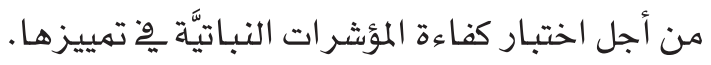

\section{- التصنيف الهجين Hybrid classification (المُوجه}

وغير الموجه Supervised and Unsupervised)

للمرئيات: قامت الدراسة بعمل تصنيف موجه وغير موجها

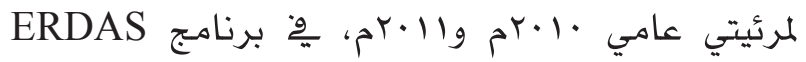
IMAGINE2011 وذلك من أجل تصنيف التغطية

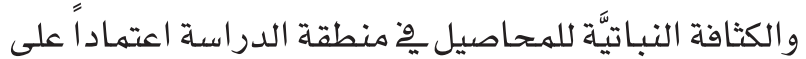

$$
\text { المؤشر ات النباتيَّة. }
$$

يؤدي إلى اختلاف قيم الخلايا Pixel بينها، وذلك اعتماداً

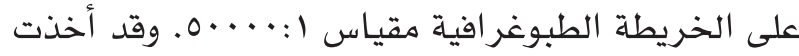

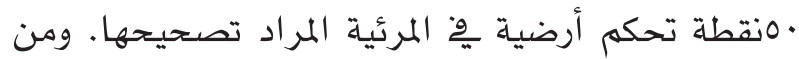

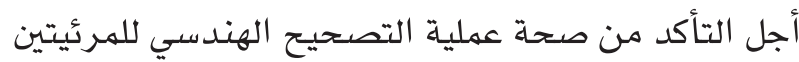
تم حساب المتوسط الحسابي لمربع الأخطاء Root mean square error (RMS $R M S=\sqrt{\left[\sum_{\mathrm{i}-1}^{\mathrm{n}}\left(\mathrm{x}_{\mathrm{img}, 1}-\mathrm{x}_{\mathrm{img}, 2}\right) 2+\sum_{\mathrm{i}-1}^{\mathrm{n}}\left(\mathrm{y}_{\mathrm{img}, 1}-\mathrm{y}_{\mathrm{img}, 2}\right) 2\right] / \mathrm{n}}$ ويقوم برنامج ERDAS IMAGINE2011 بحساب هذه المعادلة مباشرة بعد القيام بعملية التصحيح، وكلما كان توقيع نقاط التحكم دقيقاً زادت نسبة صحة التصحيح الهندسي.

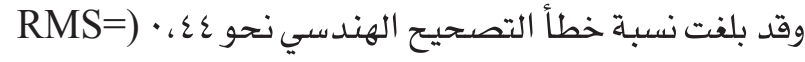
0.44)، وهي أقل نسبة خطأ تم الوصول إليها.

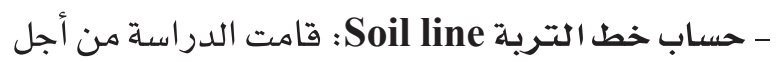
حساب خط التربة باقتطاع منطقة خالية من النباتات تغطي التربة جميع أجز ائها، وذلك من مرئيتي تطبيق معادلة خط التربة على المنطقة المقتطعة وِّْ برنامج Idrisi Taiga16.0 و والتي هي على النحو الآتي: NIRsoil $=$ a Rsoil + b ويبين جدول (r) معاملات خط التربة (معاملات

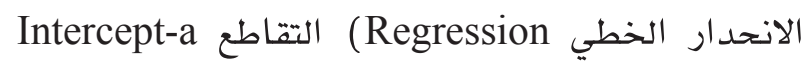
والانحدار Slope-b، و يلاحظ رغم اختلافهما بين

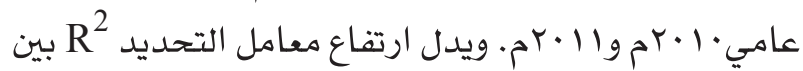
نطاقي الأشعة الحمر اء Red والأشعة تحت الحمبر الحمر اء القريبة التحدية NIR وْ العامين على تجانس تربة المنطقة المختارة. جدول (Y) معاملات خط التربة.

\begin{tabular}{|c|c|c|c|c|}
\hline 2011/4/25 & 2010/6/6 & معاملات خط التربة & الوصف & نوع التربة \\
\hline 0,019187 & 0,032385 & intercept-a & \multirow{4}{*}{ كمتفير مستقل الأشعراء } & \multirow{4}{*}{ تربة رملية جافة } \\
\hline 1,118554 & 1,090057 & slope- $b$ & & \\
\hline 0,973 & 0,957 & $R$ & & \\
\hline 0,948 & 0,916 & $R^{2}$ & & \\
\hline
\end{tabular}

- تحديد ملاءمة المؤشرات النباتيَّة: استخدمت الدراسة

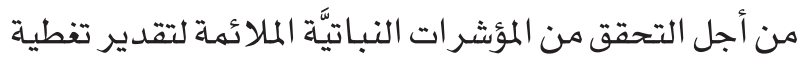

وكثافة المحاصيل، وظيفية Accuracy assessment، إحدى وظائف برنامج ERDAS IMAGINE2011 التصني تعطي دقة تصنيف المؤشر النباتي للكثافة النباتيَّة بالنسبة المئوية وبمعامل كابا، وذلك بإدخال • جrنقطة معاينة.
- اقتطاع منطقة الدراسة: استخدمت وظيفة Subset

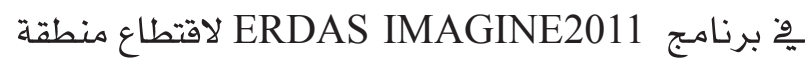
الدراسة من مرئيتي SPOT-5 ثم تم عمل Mask للمرئية

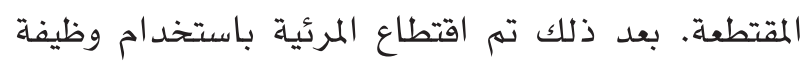
Operator .Mask 
وقد تبين أن أعلى نسبة تفطية نباتية للمحاصيل الزراعية

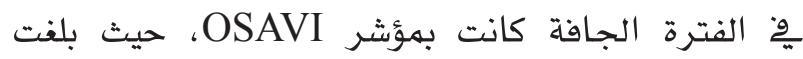

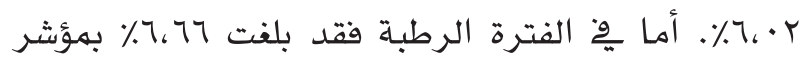

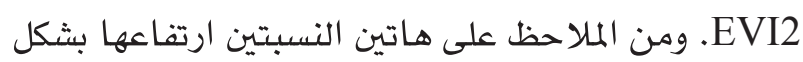

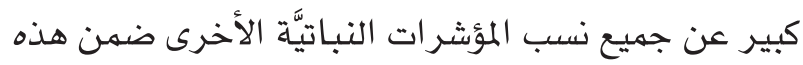

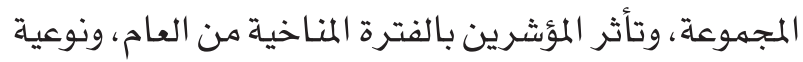

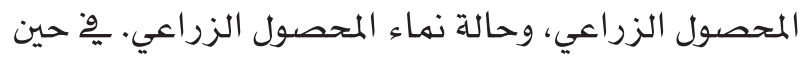
أن أقل نسبة تفطية نباتية للمحاصيل الزراعية كانت بهؤشر المراء MGNDVI

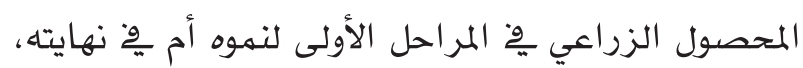

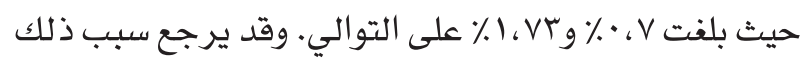

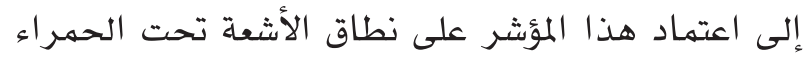
المتوسطة SWIR، الذي تقل قدرته على تمييز المحاصيل الزراعية ِِّْ منطقة الدراسة.

V- المناقشتة والنتائح: - كفاءة المؤشرات النباتيَّة الطيفيَّة ِِّْ تقدير تغطية

المحاصيل الزراعية بِّْ منطقة الهَدَا:

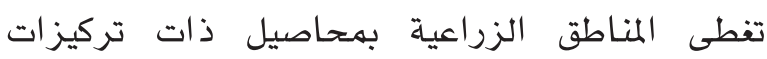

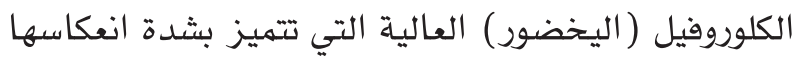

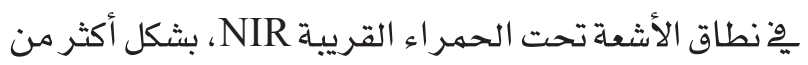
النباتات الطبيعية. ونتيجة لاعتماد أغلب المؤشرات النباتيَّة النيّة

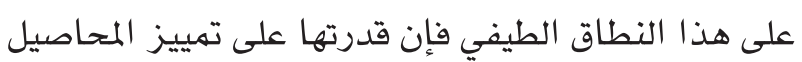
الزراعية تزيد عن قدرتها على تمييز النباتات الطبيعية،

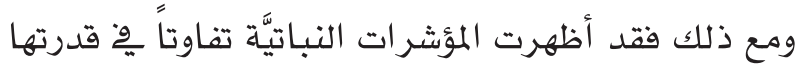
على تمييزها، وذلك على النحو الآتي:

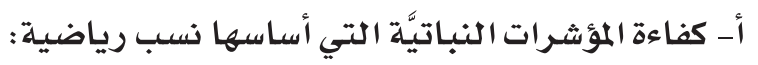

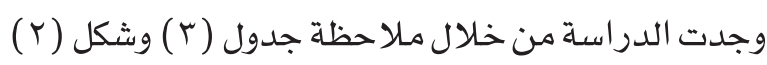

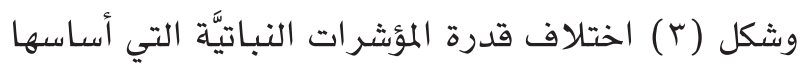

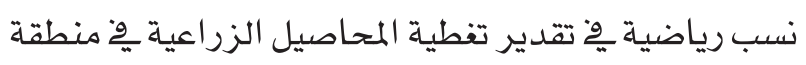

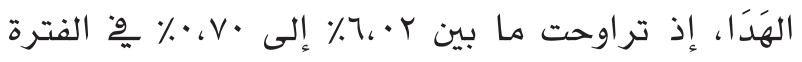

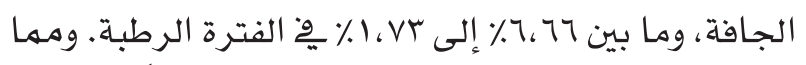

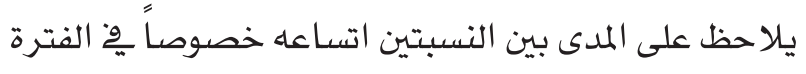

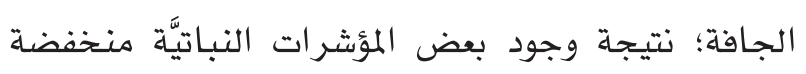

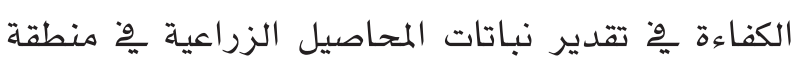
الدراسة.

جدول (r) تقدير التفطية النباتيَّة للمحاصيل الزراعية يوْ منطقة الهَدَا.

\begin{tabular}{|c|c|c|c|c|c|c|c|}
\hline \multicolumn{3}{|c|}{ الفترة الرطبة (فصل الربيع) IIrم } & \multicolumn{3}{|c|}{ الفترة الجافة (فصل الصيف) · +rrم } & \multirow[b]{2}{*}{ النباتير } & \multirow[b]{2}{*}{ المؤشـرات أقسام } \\
\hline | الزراعية ( مساطقة & النباتي ( الغطاء & 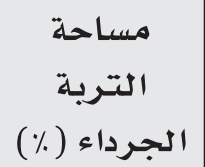 & 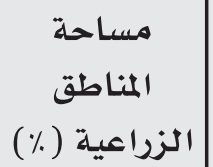 & 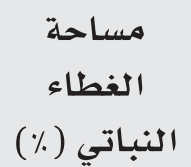 & 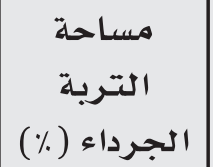 & & \\
\hline 6,66 & 65,65 & 27,69 & 4,28 & 68,89 & 26,83 & EVI2 & \multirow{6}{*}{ ألمؤشراتيَّة التي } \\
\hline 5,46 & 72,90 & 21,64 & 4,76 & 76,64 & 18,60 & GEMI & \\
\hline 5,74 & 66,25 & 28,01 & 5,36 & 60,31 & 34,33 & IPVI & \\
\hline 1,73 & 61,99 & 36,28 & 0,70 & 57,96 & 41,34 & MGNDVI & \\
\hline 5,74 & 65,87 & 28,39 & 5,36 & 60,31 & 34,33 & NDVI & \\
\hline 5,61 & 66,72 & 27,67 & 6,02 & 61,16 & 32,82 & OSAVI & \\
\hline 5,53 & 67,54 & 26,93 & 4,52 & 67,92 & 27,56 & MSAVI1 & \multirow{4}{*}{ المؤشرات النباتيَة } \\
\hline 4,39 & 77,96 & 17,65 & 3,78 & 80,05 & 16,17 & TSAVI2 & \\
\hline 5,58 & 66,30 & 28,12 & 5,18 & 60,99 & 33,83 & WDRVI & \\
\hline 5,26 & 68,19 & 26,55 & 5,00 & 64,46 & 30,54 & WDVI & \\
\hline 5,17 & 67,93 & 26,89 & 4,49 & 65,86 & 29,63 & \multicolumn{2}{|c|}{ المتوسط الكلي } \\
\hline
\end{tabular}


شكل (r) تقدير التفطية النباتيَّة للمحاصيل الزراعية ِِّ منطقة الهَدَا.

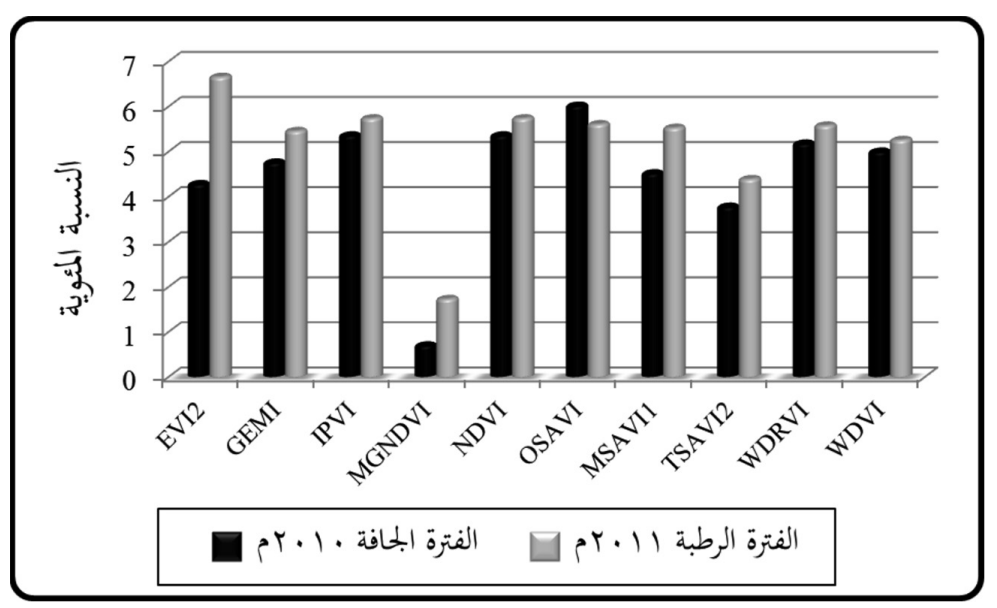

المؤشرات النباتيَّة للمحاصيل الزراعية عندما تختلط بتربة جرداء. ومع تغيير حالة المحصول الزراعي؛ نتيجة نموه وزيادة درجة كثافة خضر ته ، استمر انخفاض قدرة المؤشرات النباتيَّة السابقة وِّ تقدير تفطية المحاصيل الزراعية مضافاً إليها مؤشر ات OSAVI، حيث سجلت نسب تفطية أعلى من نسبة المتوسط الكلي، تراوحت ما بين عV،0٪ إلى rץ، \%٪.
كما اتضح انخفاض كفاءة مؤشري IPVI, NDVI تقدير المحاصيل الزراعية ِوْ الفترة الجافة بهنطقة

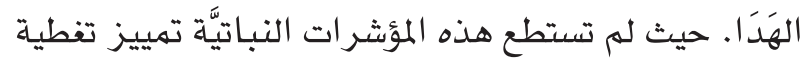

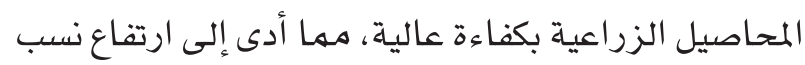
تغطيتها عن نسبة المتوسط الكلي. إذ تر اوحت نسب تغطيتها

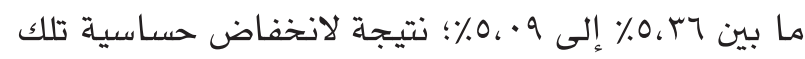

شكل (ب) كفاءة المؤشر ات النباتيَّة الطيفيَّة وِّ تقدير تغطية المحاصيل الزراعية بهنطقة الهَدَا.

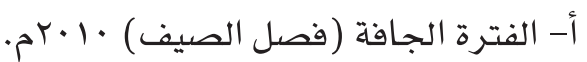

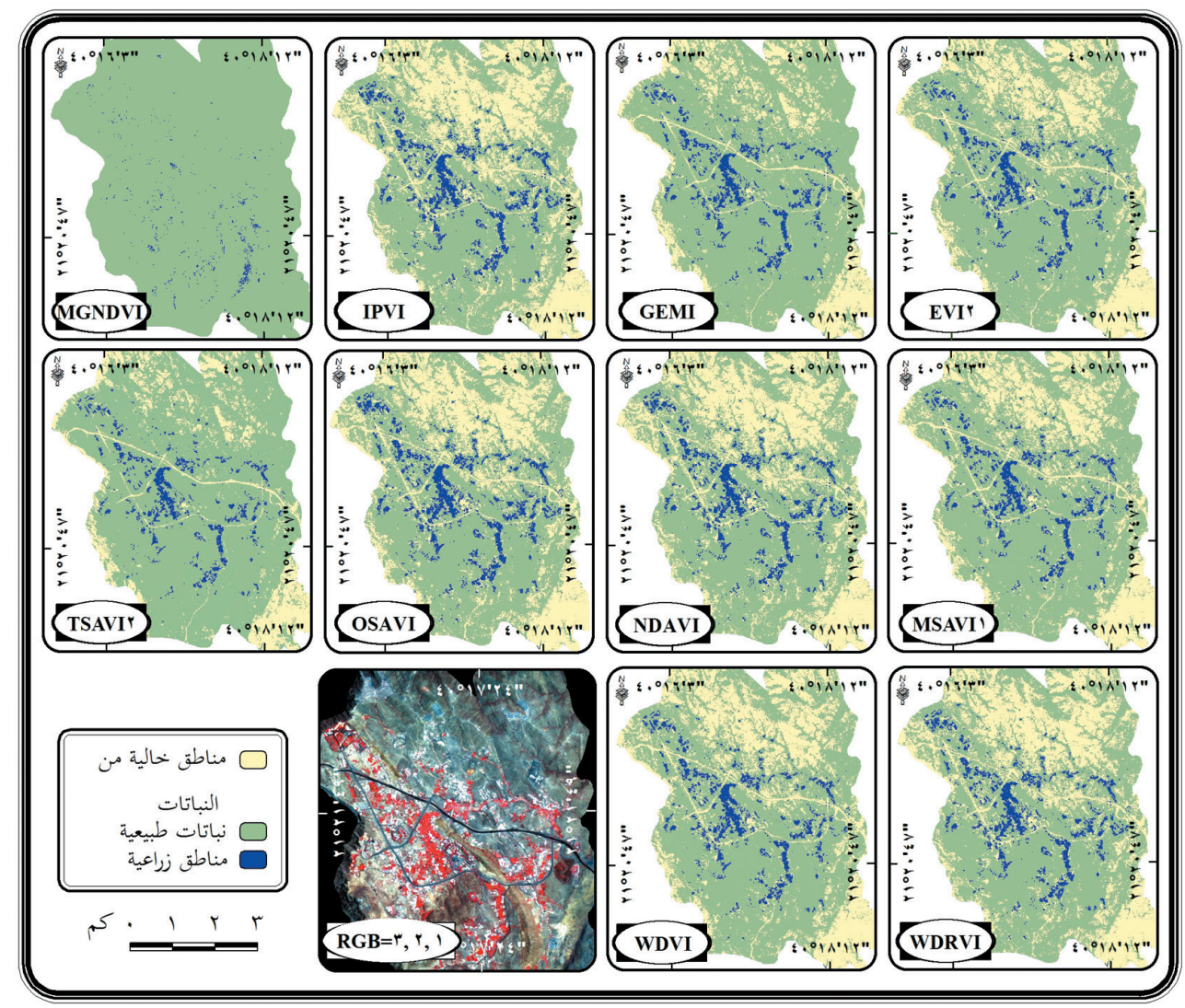


تابع شكل (r) كفاءة المؤشر ات النباتيَّة الطيفيَّة ِِّْ تقدير تفطية المحاصيل الزراعية بهنطقة الهَدَا.

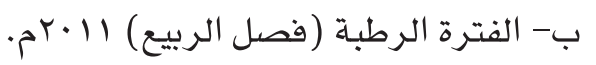

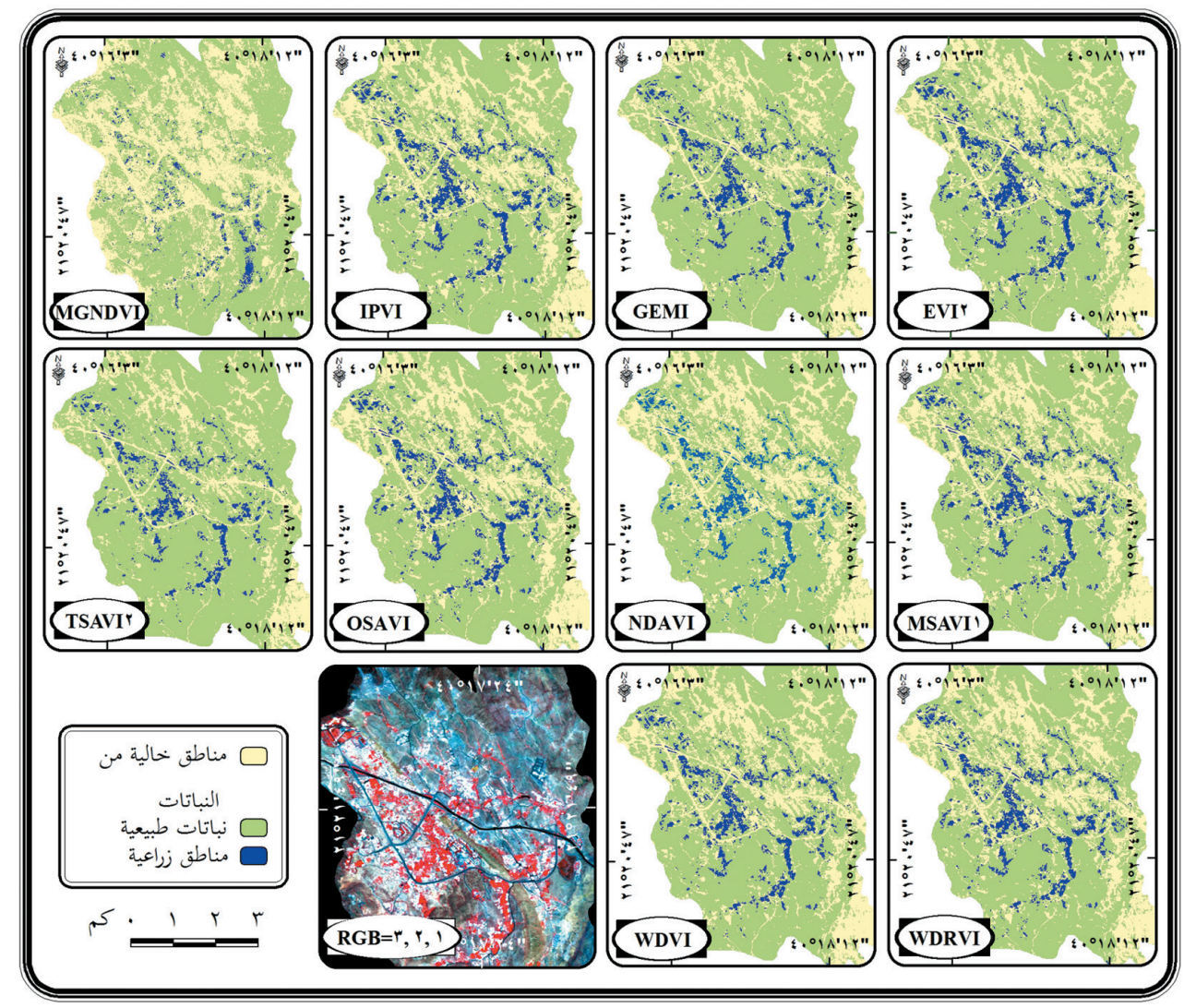

إلى

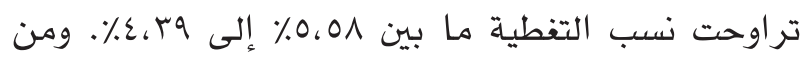

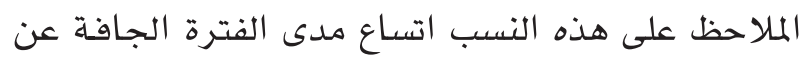

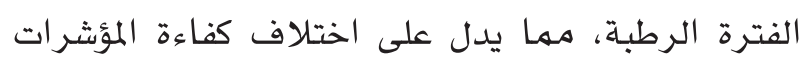

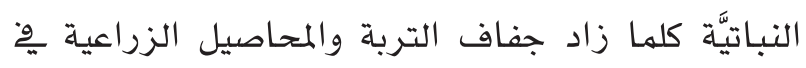

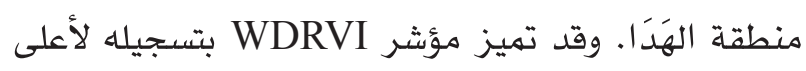

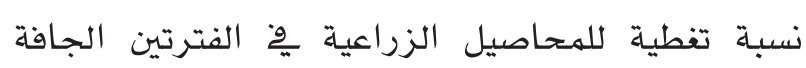
والرطبة. كما وجد أن أقل نسبة تفطية للمحاصيل الزراعية

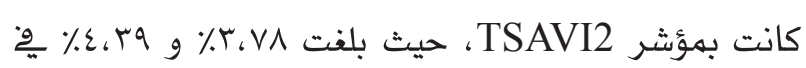

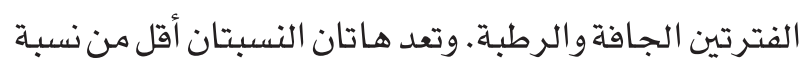

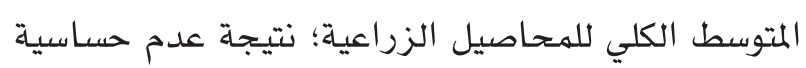
مؤشر TSAVI2 للمحاصيل الزراعية، خصوصاً ما كان

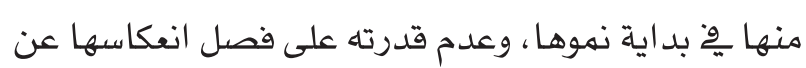

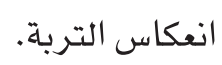
وقد استطاعت أغلب المؤشرات النباتيَّة ضهن هذه المَه المجموعة كالمجموعة السابقة تقدير تغطية المناطق الزراعية بكفاءة عالية. حيث سجلت بوْ الفترة الجافة مؤشري
وقد ظهرت كفاءة مؤشرا EVI2, GEMI

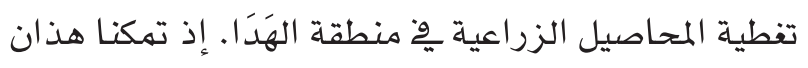

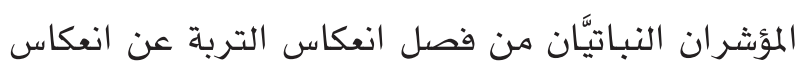

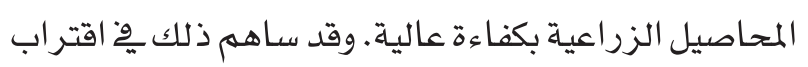

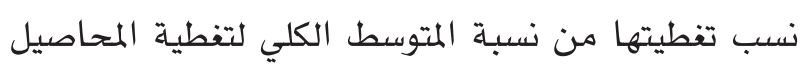

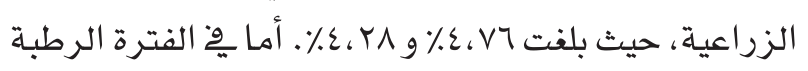

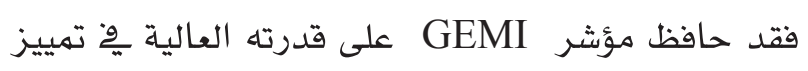
المحاصيل الزراعية، حيث بلفت نسبة تفطية هذا المؤشر

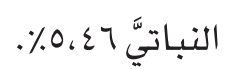
ب- كفاءة المؤشرات النباتيَّة التي أساسها مسافة بين

\section{نطاقي NIR/Red:}

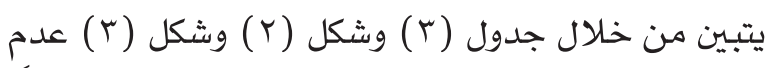

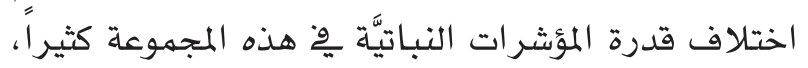

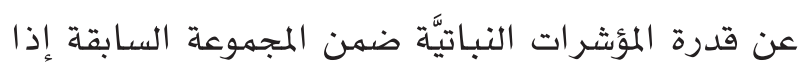

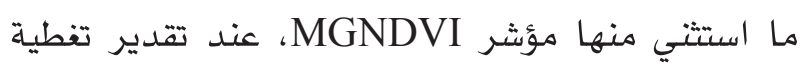

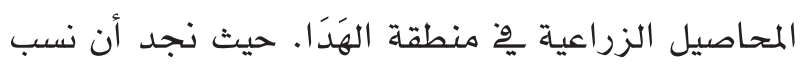

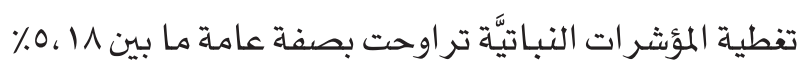


على استبعاد تأثير سطوع التربة عنها . كما أظهرت المؤشرات

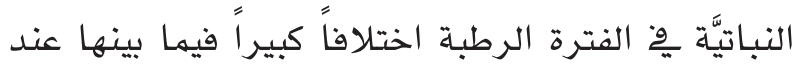
تقدير المحاصيل الفقيرة، إذ تراوحت نسب تغطيتها ما بين

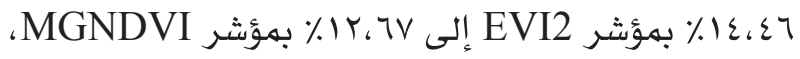

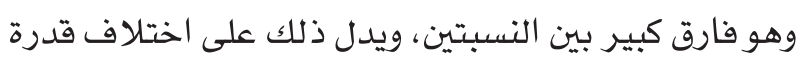
المؤشرات النباتيَّة، وعدم تمكن مجمهوعة منها لمبن على تمييز

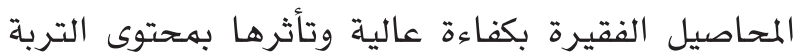
من الأسمدة ورطوبتها. كما يلاحظ اختلاف النسب بين

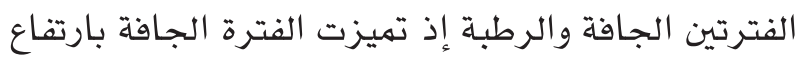

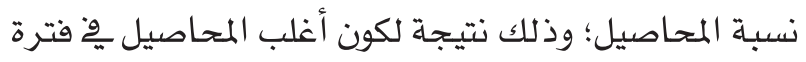

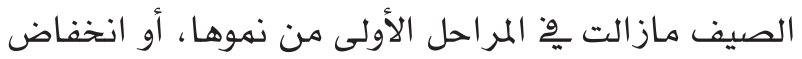

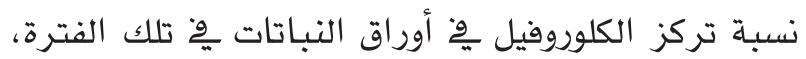
واعتمادها فقط على الري بعكس فترة الربيع.

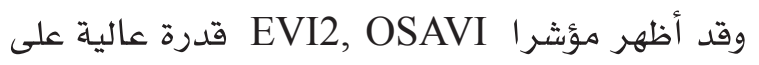
تمييز المحاصيل الفقيرة وِّ الفترة الجافة بهنطقة الهََّا.

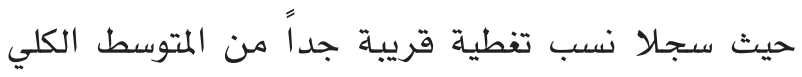

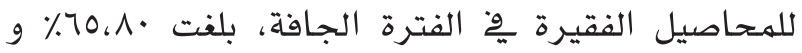
9 • 9 70٪؛ وذلك نتيجة لتقارب قدرة هذين المؤشرين النباتيَّن

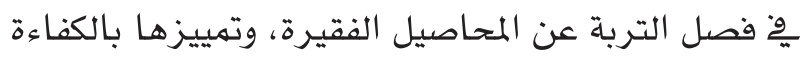

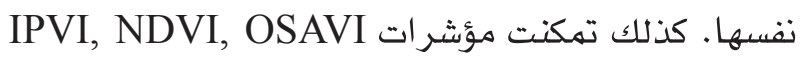
وِّ الفترة الرطبة من تقدير المحاصيل الفقيرة
MSAVI1، WDVI

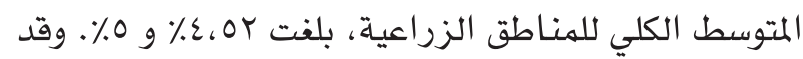
تمكنا هذان المؤشران النباتيَّن من تقدير تفطية المحاصيل

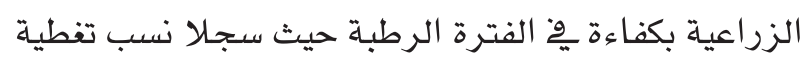

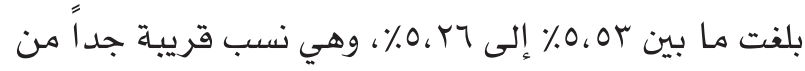

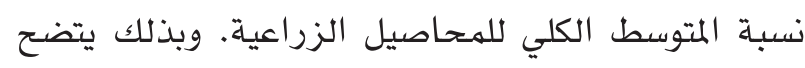

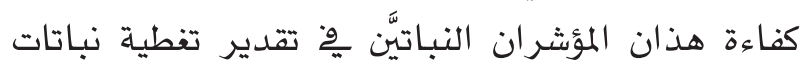

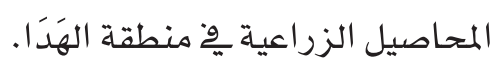

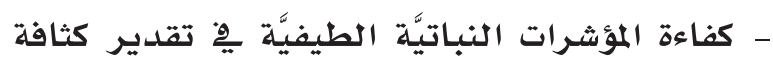
المحاصيل الزراعية بهنطقة الهَدَا:

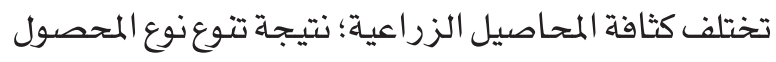

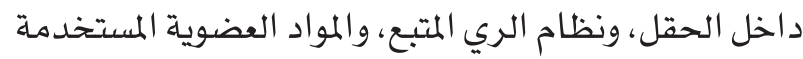

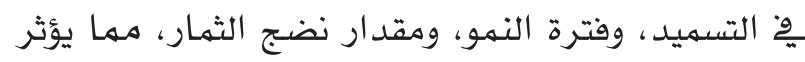

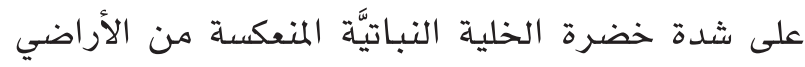

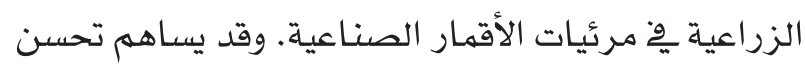

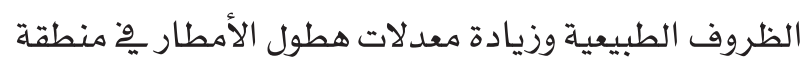

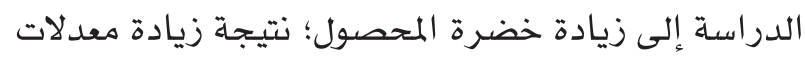
نسبة الكلوروفيل (اليخضور) موِّ أوراق النبات، هما يؤنثر

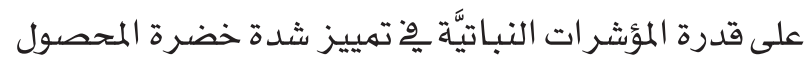

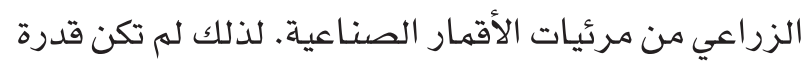

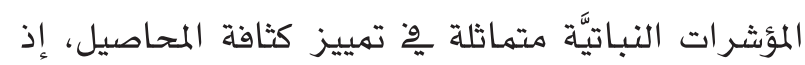
تباينت من مؤشر نباتي إلى آخر ، وذلك على النحو الآتي:

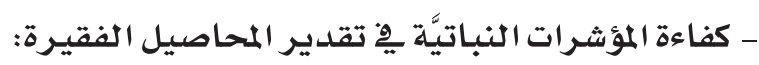

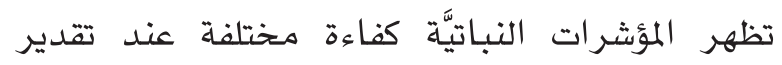

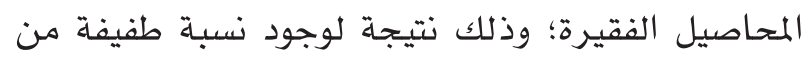

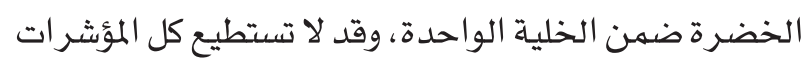

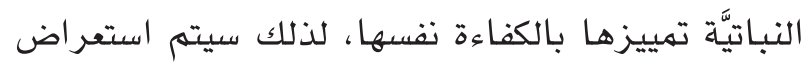

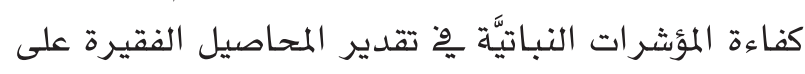

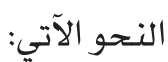
أ- كفاءة المؤشرات النباتيَّة التي أساسها نسب رياضية:

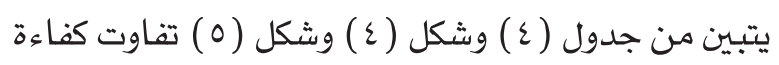

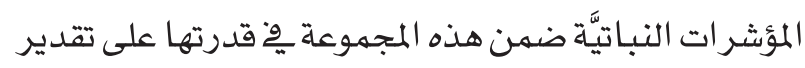

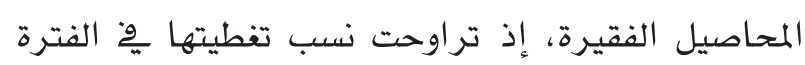

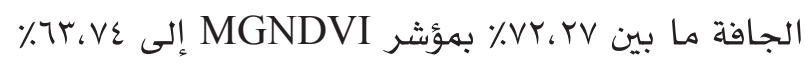
بمؤشر GEMI. ويعد المدى بين النسبتين واسعاً نسبياً؛

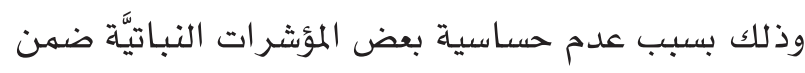

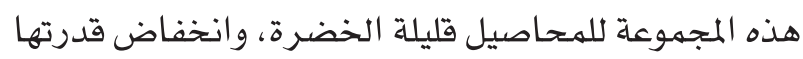


جدول (ع) تقدير كثافة المحاصيل الزراعية بهنطقة الهَدَا.

\begin{tabular}{|c|c|c|c|c|c|c|c|}
\hline \multicolumn{3}{|c|}{ 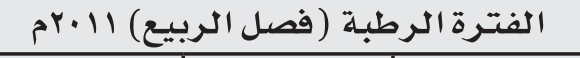 } & \multicolumn{3}{|c|}{ الفترة الجافة (فصل الصيف) • •l. } & \multirow[b]{2}{*}{ النباتي } & \multirow[b]{2}{*}{ المؤشرات أقسـام } \\
\hline كثيفة ( ) محاصيل & متوسطة محثة & فقيرة ( محاصيل & كثيفة ( محاصيل & متوسطة محثة & فقيرة (٪) & & \\
\hline 27,96 & 57,58 & 14,46 & 5,97 & 28,23 & 65,80 & EVI2 & \multirow{6}{*}{ 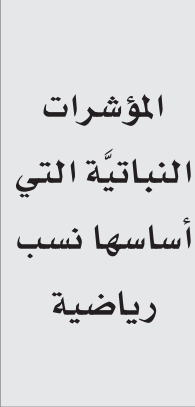 } \\
\hline 30,85 & 54,38 & 14,77 & 6,15 & 30,11 & 63,74 & GEMI & \\
\hline 28,85 & 57,30 & 13,85 & 7,69 & 28,45 & 63,86 & IPVI & \\
\hline 24,38 & 62,95 & 12,67 & 4,99 & 22,74 & 72,27 & MGNDVI & \\
\hline 28,85 & 57,30 & 13,85 & 7,69 & 28,45 & 63,86 & NDVI & \\
\hline \multirow[t]{2}{*}{28,60} & 57,71 & 13,69 & 7,22 & 27,69 & 65,09 & OSAVI & \\
\hline & 28,61 & 57,62 & 13,77 & 6,10 & 28,70 & 65,20 & \multirow{4}{*}{ 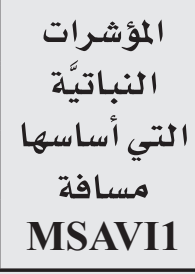 } \\
\hline 26,24 & 59,67 & 14,09 & 6,08 & 25,90 & 68,02 & TSAVI2 & \\
\hline 28,53 & 57,68 & 13,79 & 6,48 & 29,14 & 64,38 & WDRVI & \\
\hline 28,63 & 56,99 & 14,38 & 5,03 & 28,83 & 66,14 & WDVI & \\
\hline 28,15 & 57,91 & 13,93 & 6,34 & 27,82 & 65,83 & \multicolumn{2}{|c|}{ المتوسط الكلي } \\
\hline
\end{tabular}

شكل (ع) تقدير كثافة المحاصيل الزراعية بهنطقة الهَدَا.

أ- الفترة الجافة (فصل الصيف) • الثم. م.

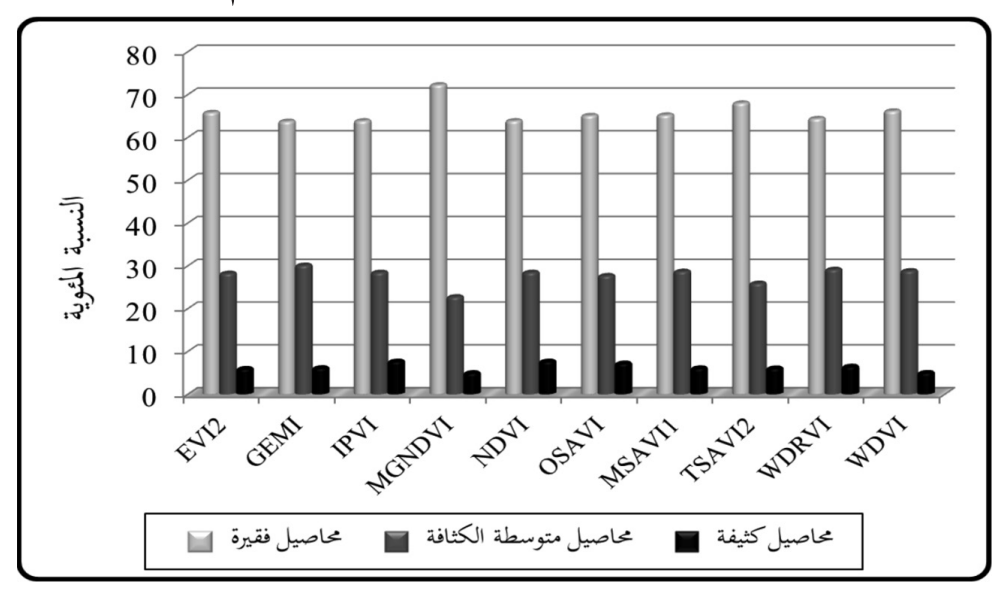

ب- الفترة الرطبة (فصل الربيع) المبام.

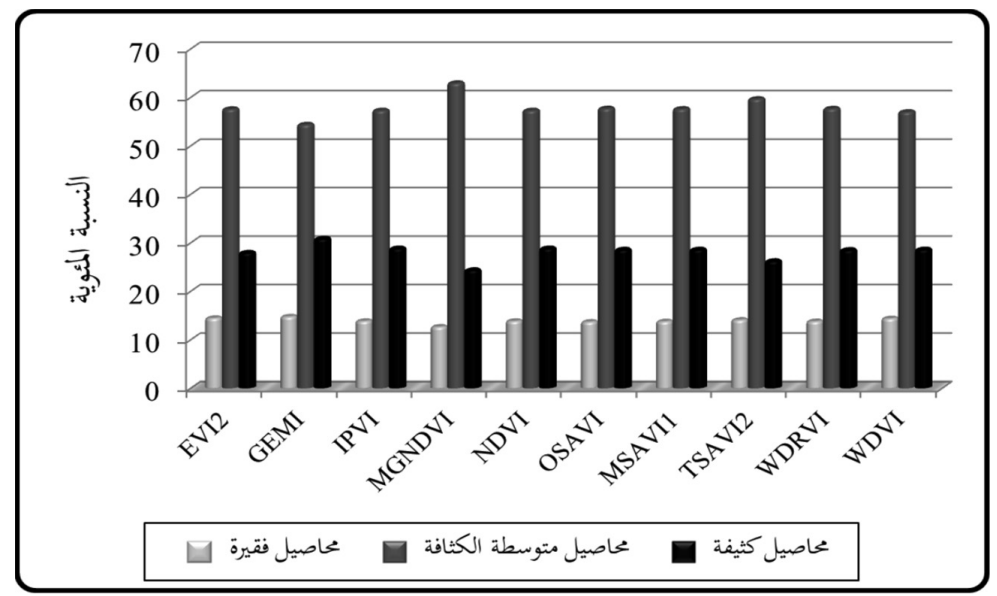


شكل (0) كفاءة المؤشر ات النباتيَّة الطيفيَّة بِّْ تقدير كثافة المحاصيل الزراعية بهنطقة الهَهَا.

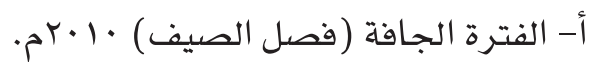

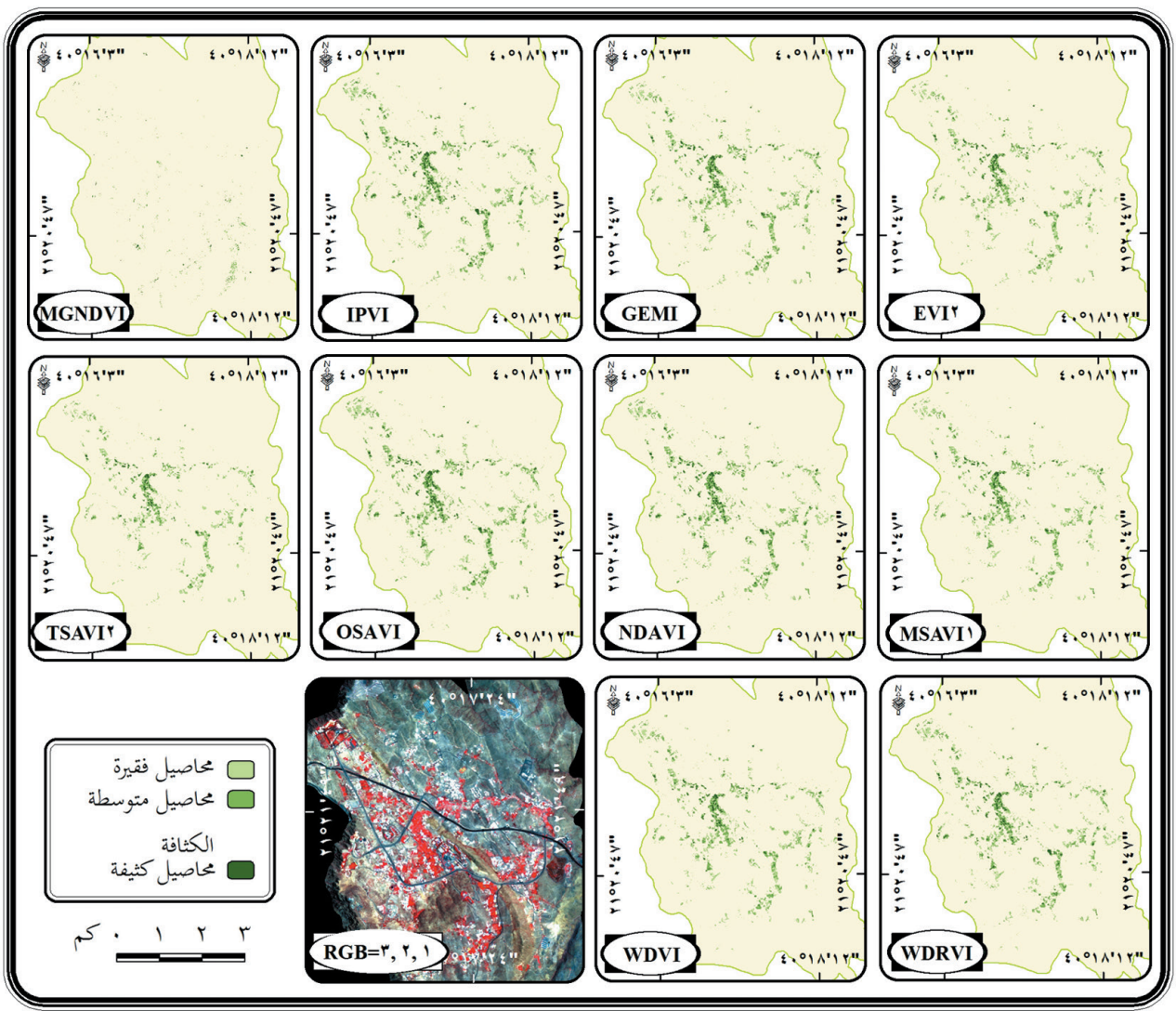

تابع شكل (0) كفاءة المؤشرات النباتيَّة الطيفيَّة بِّ تقدير كثافة المحاصيل الزراعية بهنطقة الهَدَا.

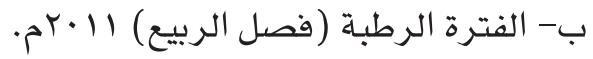

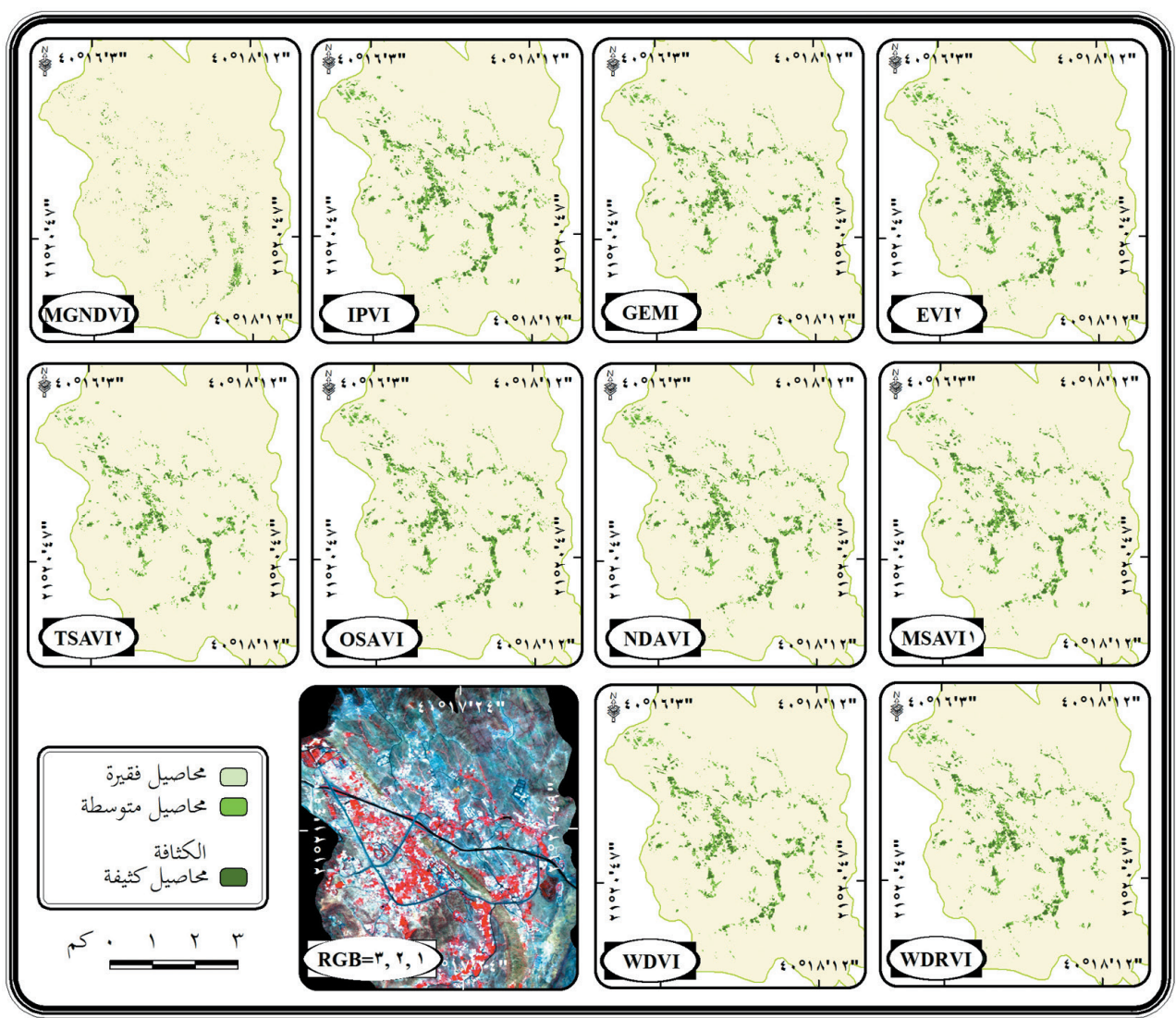


الفقيرة على مرئيات الأقمار الصناعية؛ نتيجة زيادة درجة خضرتها وتقارب المحاصيل، وقلة مساحة التربة الجرداء التي تفصل بين المحاصيل. ومح ذلك تظهر المؤشر ات ات النباتيَّة

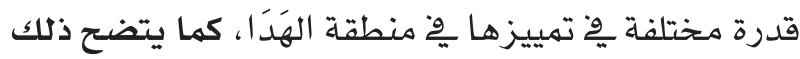
على النحو الآتي: أ- كفاءة المؤشرات النباتيَّة التي أساسها نسب رياضية:

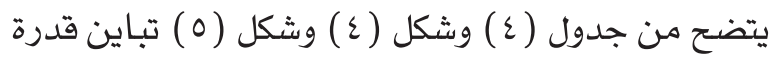

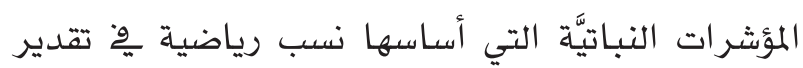
المحاصيل متوسطة الكثافة، إذ وجد أن نسب تغطيتها

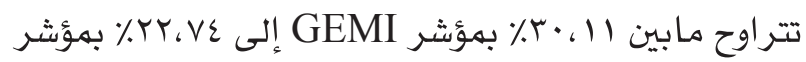
MGNDVI المؤشرات النباتيَّة ِّْ هذه المجموعة للمحاصيل، خصوصاً مؤشر MGNDVI الذي انخفضت قدرته على تمييز

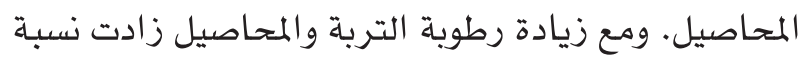
تفطية المحاصيل متوسطة الكثافة، حيث تراوحت نسبها

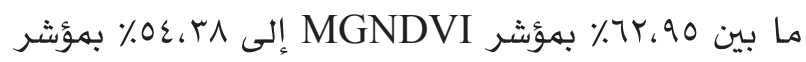
GEMI

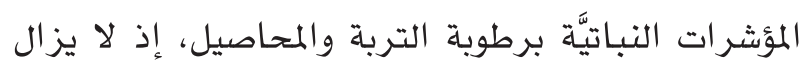
بعضها غير قادر على تمييز المحاصيل متوسطة الخضرة.

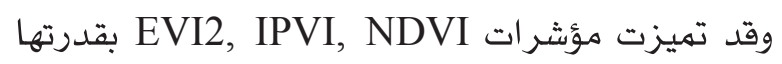
العالية على تقدير تغطية المحاصيل متوسطة الكثافة بو منطقة الهَدَا؛ وذلك لاقتراب نسبة تفطيتهما بوْْ الفترة الجافة من المتوسط الكلي للهحاصيل متوسطة الكثافة،

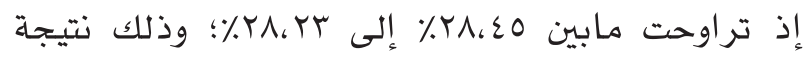

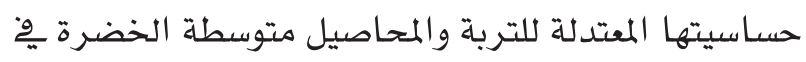
المنطقة. كذلك ارتفعت كفاءة المؤشرات السابقة بالإضافة إلى مؤشر OSAVI وْْ تقدير تغطية المحاصيل متوسطة كنة

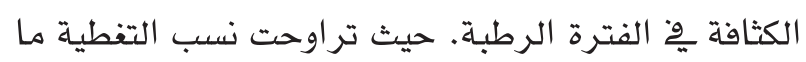

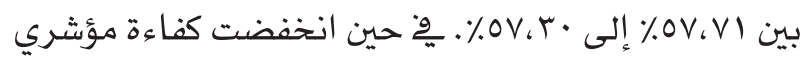
GEMI GEMI, OSAVI تقدير تغطية المحاصيل متوسطة الكثافة. ب- كفاءة المؤشرات النباتيَّة التي أساسها مسافة المقافة بين نطاقي NIR/Red:

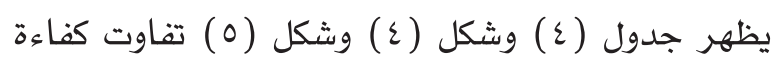

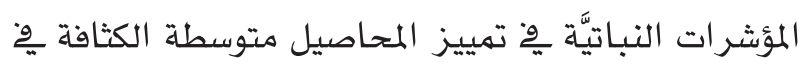

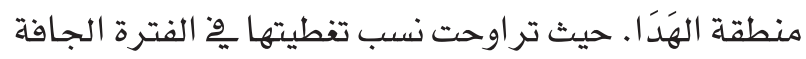

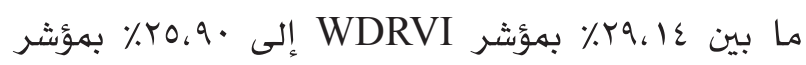

بكفاءة عالية. حيث أعطت هذه المؤشرات نسب تفطية نباتيَّة قريبة جداً من المتوسط الكلي للمحاصيل الفقيرة،

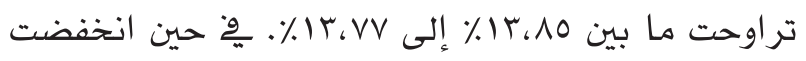

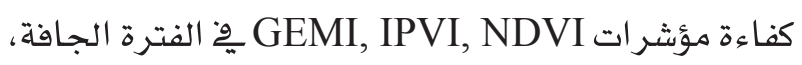
ومؤشري EVI2, GEMI وِّ الفترة الرطبة، عند تقدير تفطية المحاصيل الفقيرة. ب- كفاءة المؤشرات النباتيَّة التي أساسها مسافة بين نطاقي NIR/Red: يتضح من جدول ( ع ) وشكل ( ع) ) وشكل (0) ماقي ) تقاوت كفاءة

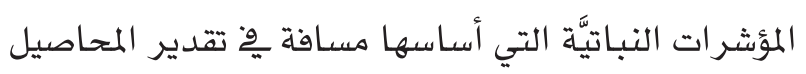

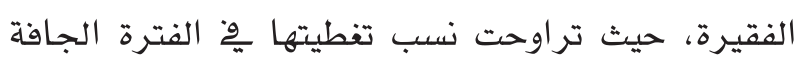

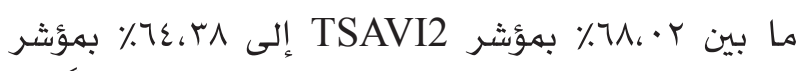
.WDRVI

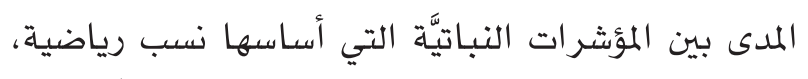

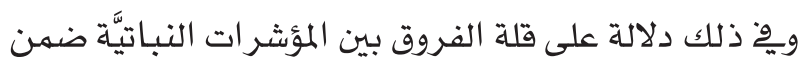

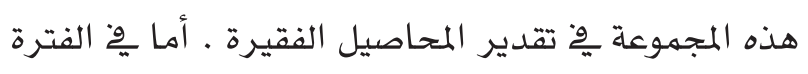

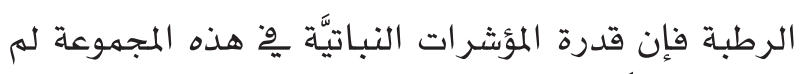

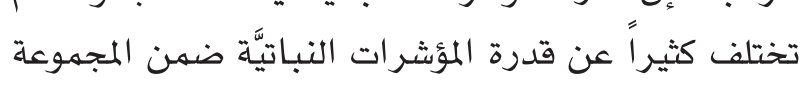

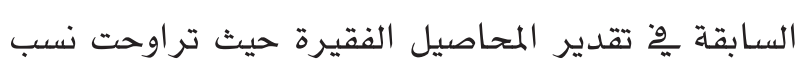

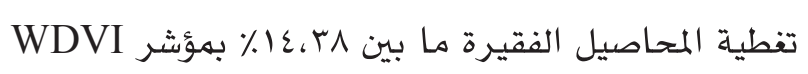

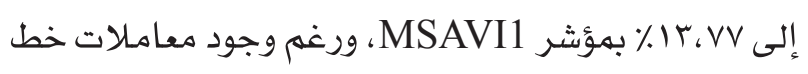

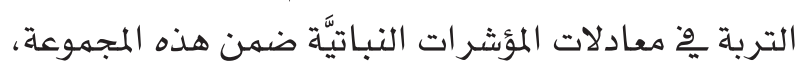

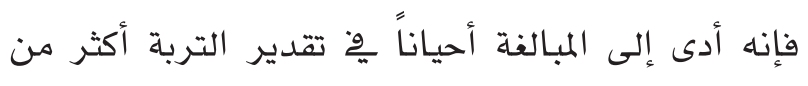
المحاصيل الفقيرة. كما أظهرت مؤشرات MSAVI1, WDRVI, WDVI الميل الفقئة الفترة الجافة، قدرة منخفضة على مؤى تمييز المحاصيل الفقيرة

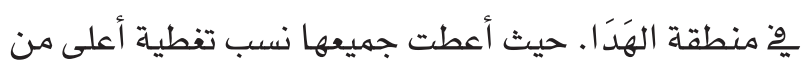

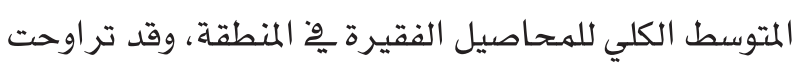

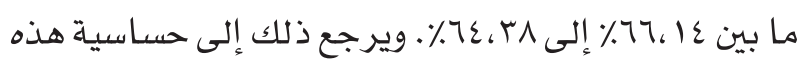

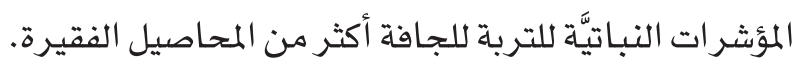

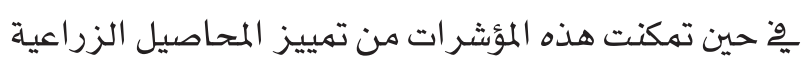

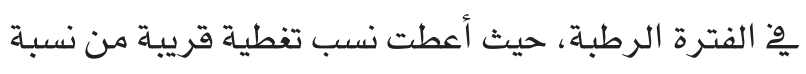

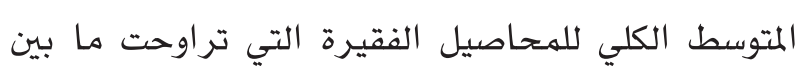

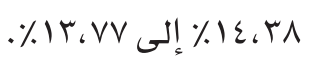
كفاءة المؤشرات النباتيَّة بوْ تقدير المحاصيل متوسطة

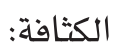
تعد المحاصيل متوسطة الكثافة أكثر وضوحاً من المحاصيل 
كفاءة عالية وِ تقدير المحاصيل الكثيفة وْ منطقة OSAVI الهََّا، إذ استطاعت هذه المؤشرات النباتيَّة تمييز تغطية المحاصيل الكثيفة بنسب قريبة جدا من المتوسط الكلي

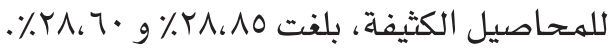

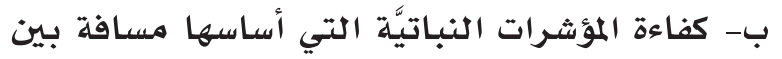
نطاقي NIR/Red: يتضح من جدول ( ع) وشكل (0) وشكل (7) و (7 ) وجود تفاوت

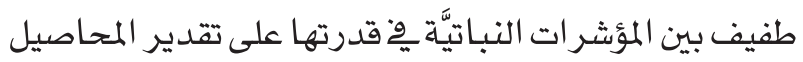

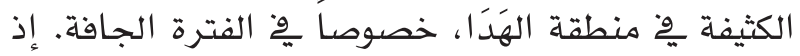

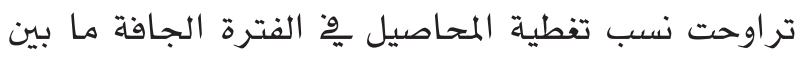

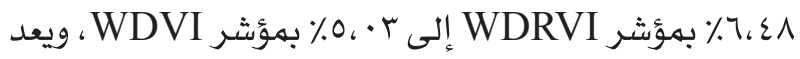

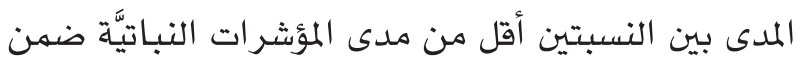
المجموعة السابقة. وِّ حين تر اوحت نسب تغطية المحاصيل

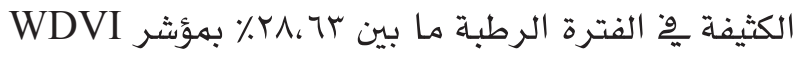

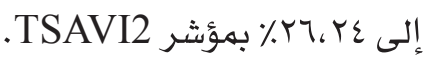
كما ظهر ارتفاع كفاءة مؤشرا MSAVI1, TSAVI2 تقدير المحاصيل الكثيفة ِِّْ الفترة الجافة بهنطقة الهَدَا.

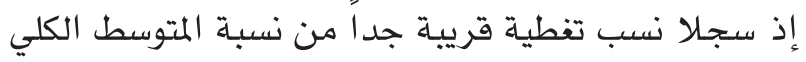

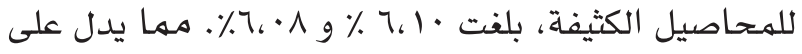

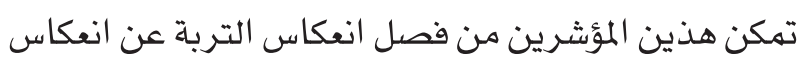

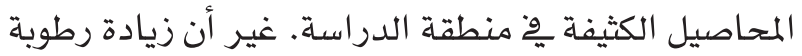

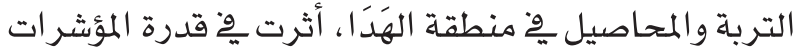

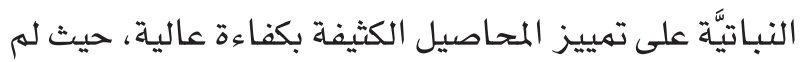
تستطع سوى مؤشري MSAV1, WRDVI من تمييزها

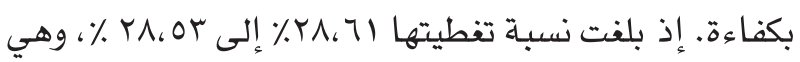
نسب قريبة جداً من نسبة المتوسط الكلي للمحاصيل الكثيفة.

\section{- المؤشرات النباتيَّة الطيفيَّة الملائمة لتقدير المحاصيل}

\section{الزراعية يِّ منطقة الهَدَاء}

تتفاوت كفاءة المؤشرات النباتيَّة الطيفيَّة فيما بينها عند النداء

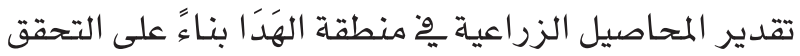
الحقلي، والتحقق بهرئيات عالية الوضوح المكاني ( •آسم)

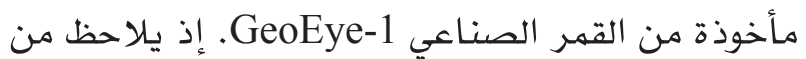
جدول (0) أن مؤشري MSAVI1, WDVI ماخِ الفترة

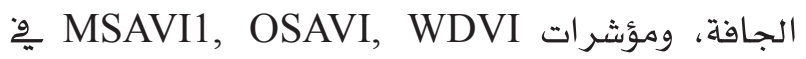
الفترة الرطبة احتلت المرتبة الأولى بِّ ملاءمتها جداً لتقدير تغطية وكثافة المحاصيل الزراعية مقارنة بالمؤشر ات النباتيَّة

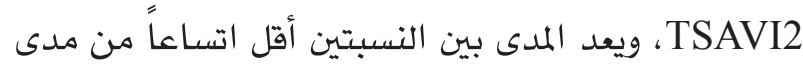

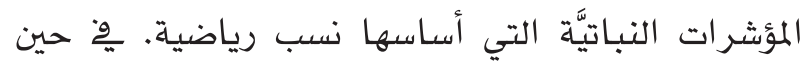
تراوحت نسب تغطية المحاصيل متوسطة الكثافة يِّ الفترة

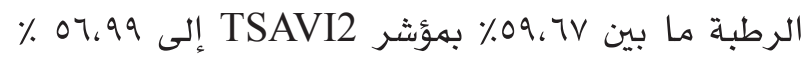

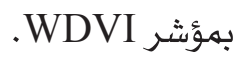
وقد تهكن مؤشرات MSAVI1, WDRVI, WDVI من تقدير المحاصيل متوسطة الكثافة بكفاءة عالية وِّ منطقة الهَدَا. حيث بلغت نسبة تغطيتها بِّ الفترة الجافة ما بين

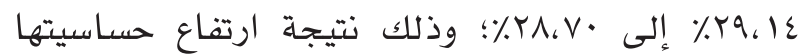
للمحاصيل متوسطة الخضرة وانخفاض حساسيتها للتربة.

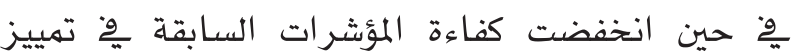
المحاصيل متوسطة الكثافة عن التربة الرطبة بكفاءة عالية

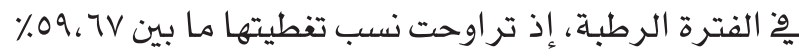
إلى \%97، 979

كفاءة المؤشرات النباتيَّة هِّ تقدير المحاصيل الكثيفة:

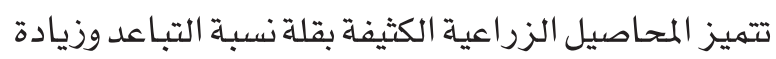

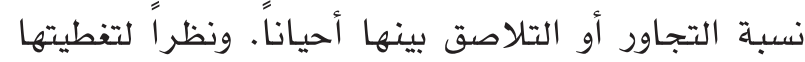

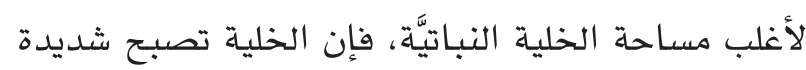
الخضرة، بحيث يسهل تهييزها على المرئيات الفضائية،

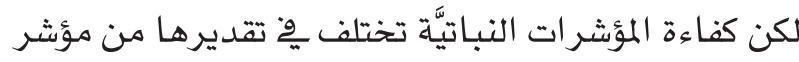

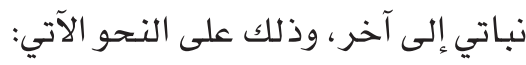
أ- كفاءة المؤشرات النباتيَّة التي أساسها نسب رئي رياضية:

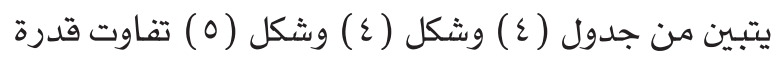

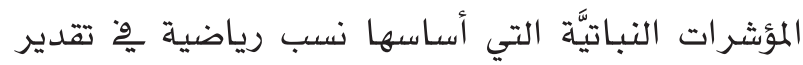

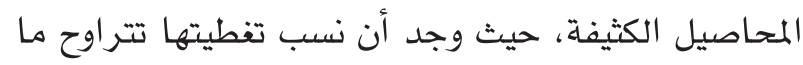

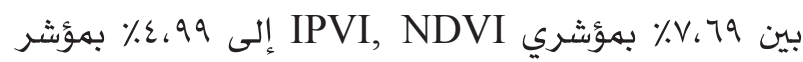

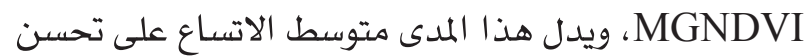

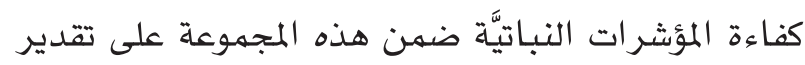
المحاصيل الكثيفة، وبشكل أفضل من قدرتها على تمييز

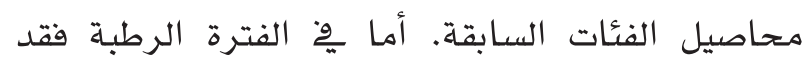

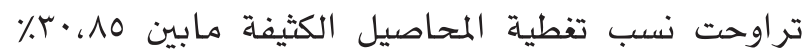

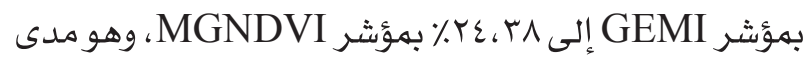
أكثر اتساعاً من مدى الفترة الجافة.

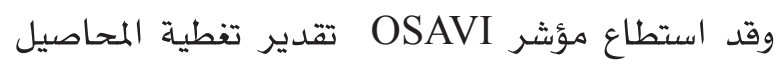

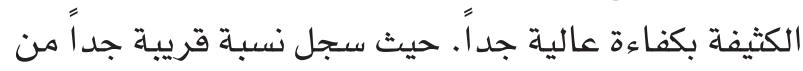

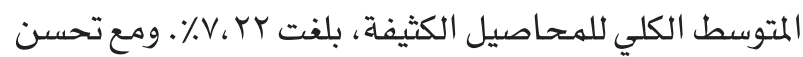

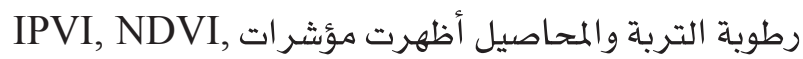


مؤشرات المرتبة الخامسة بأنها غير ملائمة لتقدير

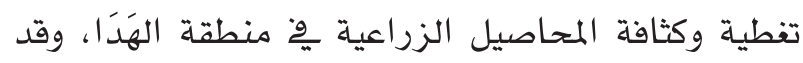

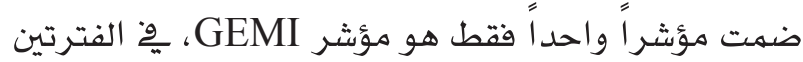

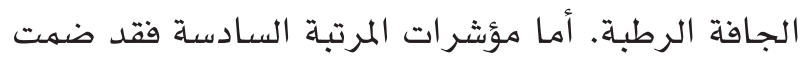

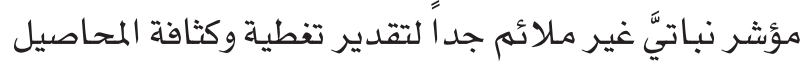

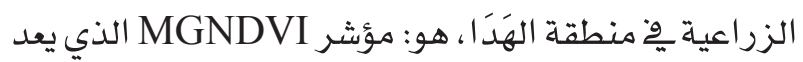

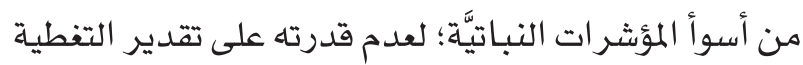

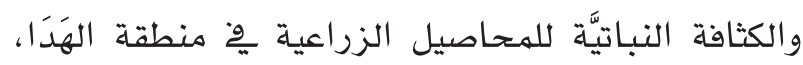
وإعطائه نتائج غير صحيحة لا يمكن للدراسة الاعتماد عليها إطلاقاً.
الأخرى. وِّحين احتل المرتبة الثانية مؤشر EVI2 عِّ الفترة الجافة، ومؤشرات NDVI, IPVI, WDRVI مِّْ الفترة الرطبة، وِّ مدى ملاءمتها لتقدير تفطية وكثافة للمحاصيل

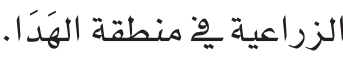

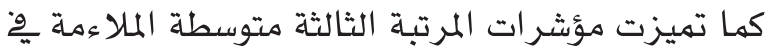
الفترة الجافة بضمها لمؤشري OSAVI, TSAVI2، وبوّن الفترة الرطبة ضمها لمؤشري EVI2, TSAVI2، ورغم الفمتئي انخفاض قدرتهما على الفصل بين التربة والمحاصيل، وتمييز فئات الكثافة النباتيَّة للمحاصيل فِّ منطقة الدراسة، فإنهما يعدان مؤشران متوسطا الملاءمة لتقدير تغطية

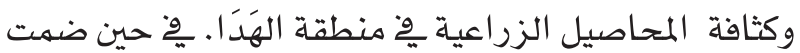

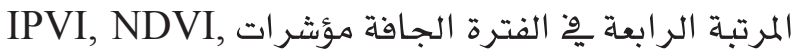
WDRVI

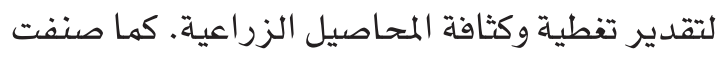

جدول (0) دقة ملاءمة المؤشر ات النباتيَّة لتقدير تفطية وكثافة المحاصيل الزراعية بِّم منطقة الهَدَا.

\begin{tabular}{|c|c|c|c|c|c|c|c|}
\hline \multicolumn{2}{|c|}{ الفترة الرطبة 11+lrم } & \multirow{2}{*}{ المؤشر } & \multicolumn{2}{|c|}{ الفترة الجافة · +1. م } & \multirow{2}{*}{ المؤشر } & \multirow[b]{2}{*}{ درجة الملاءمـة } & \multirow[b]{2}{*}{ المرتبة } \\
\hline معامل كابا & المئوية (٪) & & معامل كابا & المئوية ( النسبـة & & & \\
\hline 0,907 & 93,03 & MSAVI1 & 0,888 & 91,11 & MSAVI1 & \multirow{3}{*}{ ملائمـة جداً } & \multirow{3}{*}{ 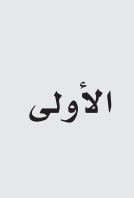 } \\
\hline 0,887 & 91,59 & OSAVI & \multirow{2}{*}{0,876} & \multirow{2}{*}{90,14} & \multirow{2}{*}{ WDVI } & & \\
\hline 0,871 & 90,14 & WDVI & & & & & \\
\hline 0,813 & 86,06 & NDVI & \multirow{3}{*}{0,867} & \multirow{3}{*}{89,42} & \multirow{3}{*}{ EVI2 } & \multirow{3}{*}{ ملائمة } & \multirow{3}{*}{ 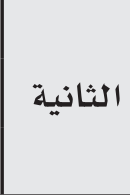 } \\
\hline 0,807 & 85,58 & IPVI & & & & & \\
\hline 0,807 & 85,58 & WDRVI & & & & & \\
\hline 0,794 & 84,13 & EVI2 & 0,754 & 80,53 & OSAVI & \multirow{2}{*}{ متوسطة الملاءمة } & \multirow{2}{*}{ الثالثة } \\
\hline 0,759 & 81,97 & TSAVI2 & 0,724 & 77,64 & TSAVI2 & & \\
\hline 0 & 0 & - & 0,667 & 73,56 & IPVI & \multirow{3}{*}{ منخفضة الملاءمة } & \multirow{3}{*}{ الرابعة } \\
\hline 0 & 0 & - & 0,667 & 73,56 & NDVI & & \\
\hline 0 & 0 & - & 0,663 & 73,32 & WDRVI & & \\
\hline 0,631 & 69,95 & GEMI & 0,510 & 61,54 & GEMI & غير ملاءمة & الخامسة \\
\hline 0,196 & 38,70 & MGNDVI & 0,165 & 33,65 & MGNDVI & غير ملاءمة جداً & السادسة \\
\hline
\end{tabular}


النباتيَّة الطيفية؛ وذلك لتفاوت فاعليتها ِِ2 فصل التربة

عن المحاصيل، إذ قد يعطي الاعتهاد على مؤشر نباتي واحد فقط نتأُج مضللة أو خاطئة عن واقع المحاصيل الزراعية

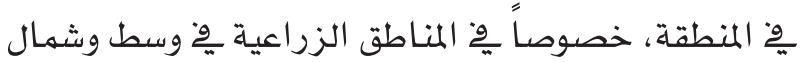

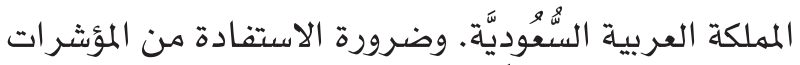

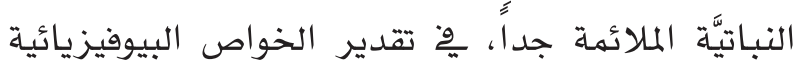
الأخرى للهحاصيل الزراعية ِِْ منطقة الهَدَا، كمؤشر مساحة الورقة، والكتلة الحيوية الخضراء، والامتصاص

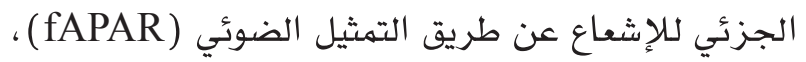
والإنتاج الزراعي، باستخد ام بيانات أقمار صناعية متعددة.

\section{المراجع:}

البلادي، عاتق غيث ( · ·عاهـ) ، معجم معالم الحجاز، الجزئيين الخامس والتاسع، دار مكة، مكة المكرمة.

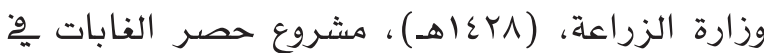
المنطقة الجنوبية الغربية من المملكة العربية السُّوُوديَّة، حصر الغابات الطبيعية يوْ المنطقة الأولى، المجلد الثاني، مدينة الملك عبد العزيز للعلوم والتقنية، الرياض.

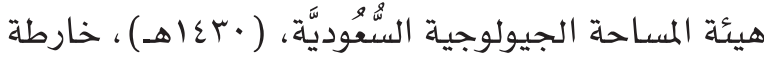

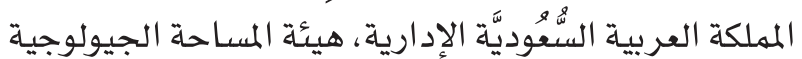

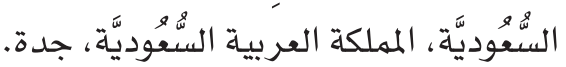

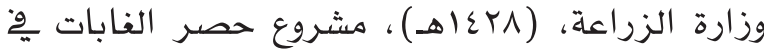
المنطقة الجنوبية الغربية من المملكة العربية السُّعُوديَّة،

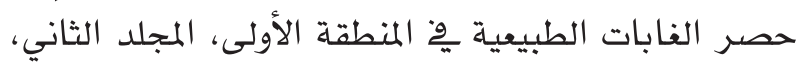

$$
\text { مدينة الملك عبد العزيز للعلوم والتقنية، الرياض. }
$$

- Aparicio, N.; Villegas, D.; Casadesus, J.; Araus, J.L. and Royo, C., (2000), Spectral vegetation indices as nondestructive tools for determining durum wheat yield, Agronomy Journal, 92, pp.83-91.

- Bannari, A. and Asalhi, H., (2004), Sensitivity Analysis of Spectral Indices to Ozone Absorption Using Physical Simulations in a Forest Environment: Comparative Study between MODIS, SPOT VÉGÉTATION \& AVHRR, <http://www.cartesia. org/geodoc/isprs2004/comm7/papers/157.pdf>

- Bannari, A.; Morin, D.; Bonn, F. and Huete, A. R. (1995), A review of vegetation indices, Remote Sensing Reviews, 13, pp.95-120.
تختلف كفاءة المؤشرات النباتيَّة فيها بينها عند تقدير خصائص المحاصيل الزراعية يِّ أي منطقة تطبق عليها تلك

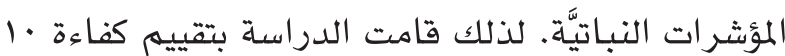
مُؤشرات نباتية طيفية وِّ تقدير المحاصيل من خلال بيانات القهر الصناعي SPOT-5، وذلك ِِّ منطقة جبلية معقدة تضاريسياً تقع شمال جبال السَّرَوَات. وتتميز هذه المنطقة الجبلية باختلاف تغطية وكثافة المحاصيل الزراعية بها التي يصعب تقديرهما بدون استخدام أدوات وأساليب تقنية الاستشعار عن بعد. وقد اعتمدت الدراسة لتحقيق ذلك على بلى بيانات القمر الصناعي SPOT-5، وقد خضعت البيانات للمعالجة پِ براهج ERDAS IMAGINE9.1, Idrisi Regress, باستخد ام وظائف Taiga16.0, ArcGIS9.2 Spatial modeler, Operator, Classification, .Overlay, Accuracy assessment, Spatial analyst وقد توصلت الدراسة إلى اختلاف كفاءة المؤشرات النباتيَّة وِ تحديد مساحة تفطية المحاصيل وِّ منطقة

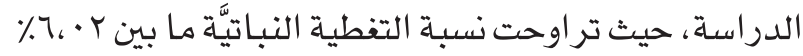

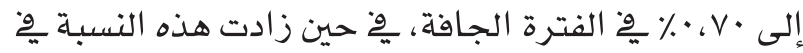
الفترة الرطبة لتتر اوح ما بين 77، 7٪\% إلى سV، I٪٪. كما اتضح انخفاض كفاءة مؤشرات IPVI, NDVI, WDRVI OSAVI, TSAVI2 الفترة الجافة، مضافاً لها مؤشرات وْْ الفترة الرطبة، لتقدير تغطية المحاصيل الزراعية، وعدم قدرتها على فصل انعكاس التربة عن انعكاس المحاصيل پِّ

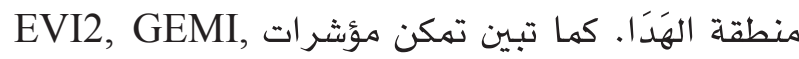
GEMI وِّ الفترة الجافة، ومؤشر MSAVI1, WDVI وِ الفترة الرطبة تقدير التفطية النباتيَّة بكفاءة. كما اتضح تقاوت كفاءة المؤشرات النباتيَّة ِِّ الفصل بين فئات كثافة المحاصيل الزراعية، وفصل انعكاسها عن انعكاس التربة.

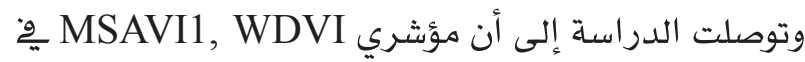
الفترة الجافة، ومؤشرات MSAVI1, OSAVI, WDVI وِّ الفترة الرطبة، هي أفضل المؤشرات النباتيَّة الملائمة وهوتة المنطقة الدراسة، ِوْ حين أن مؤشر MGNDVI هو أسوأ

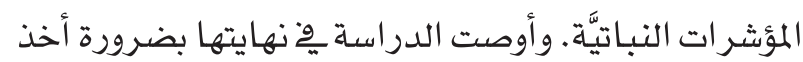
أكثر من مؤشر نباتي طيفي عند استخد ام المؤشر ات النباتيَّة الطيفية ِوْ تقدير أي خاصية من خصائص المحاصيل الزراعية بِ المناطق التي له تختبر فيها كفاءة المؤشرات 
biophysical characteristics of vegetation, Journal of Plant Physiology 161, pp.165 -173.

- Gumz, M. and Weller, S., C.(2005), Using Spectral Vegetation Indices to Differentiate Weeds and Mint in Remote Sensing Images, Site Specific Management Center Newsletter, Purdue University, April, 2005.

- Haboudane, D.; Miller,J.R.; Tremblay,N.; ZarcoTejada, P.J. and Dextraze, L., (2002), Integrated narrow-band vegetation indices for prediction of crop chlorophyll content for application to precision agriculture, Remote Sensing of Environment, 81, pp.416- 426.

- Haboudane, D ; Miller, J.R.; Pattey, E.; ZarcoTejada, P.J. and Strachan I.B., (2004), Hyperspectral vegetation indices and novel algorithms for predicting green LAI of crop canopies: Modeling and validation in the context of precision agriculture,

Remote Sensing of Environment, 90, pp.337 -352.

- Houlès. V. ; El Hajj M. and Bégué A., (2006), Radiometric normalization of a spot 4 and spot 5 time series of images (islereunion) for agriculture applications, ISPRS Commission Technique I. Symposium, Marne-la-Vallée, FRANCE (032006/07/), no 181 (57 p.), pp. 31 -37.

- Huete, A.; Justice, C.; and Leeuwen, W. V., (1999), MODIS vegetation index (MOD 13): algorithm theoretical basis document (ATBD), Version 3. <http://modis.gsfc.nasa.gov/data/atbd/ atbd_mod13.pdf>

- Jackson, R.D. and Huete, A.R., (1991), Interpreting vegetation indices, Preventive Veterinary Medicine, 11, pp.185 -200. Elsevier Science Publishers B. Y., Amsterdam.

- Ji, L. and Peters, A J., (2007), Performance evaluation of spectral vegetation indices using a statistical sensitivity function, Remote Sensing of Environment, 106, pp.59- 65

- Jiang, Zhanangyan; Huete, Alfredo R.; Kamel,
- Baret, F. and Guyot, G., (1991), Potentials and limits of vegetation indices for LAI and APAR assessment, Remote Sensing of Environment, 35, pp.161 -173.

- Chopping, M.; Su, L.; Rango, A.; Martonchik, J.; Peters, D. and Laliberte, A., (2008), Remote sensing of woody shrub cover in desert grasslands using MISR with a geometric-optical canopy reflectance model, Remote Sensing of Environment, 112 , pp. 19-34.

- Clevers, J. G., (1989), The application of a weighted infrared-red vegetation index for estimating leaf area index by correcting soil moisture, Remote Sensing of Environment, 29, pp.25 -37.

- Colditz, R. R.; Conrad, C.; Wehrmann, T.; Schmidt, M. and Dech, S., (2007), Analysis of the quality of collection 4 and 5 vegetation index time series from MODIS, <http://www.isprs. org/proceedings/XXXVI/2-C43/www.itc.nl/ issdq2007/proceedings/Session $\% 20420 \%$ Geo $\% 20$ Information\%20Theory/paper\%20colditz.pdf>

- Crippen, R.E., (1990), Calculating the vegetation index faster, Remote Sensing of Environment, 34 (1), pp. 71- 73 .

- Elvidge, C. and Lyon, R. J., (1985), Influence of rock-soil spectral variation on the assessment of green biomass, Remote Sensing of Environment,17, pp.265 -279.

- Gilabert, M.A.; Gonza'lez-Piqueras, J.; GarcíaHaro, F.J. and Meli, J., (2002), A generalized soiladjusted vegetation index, Remote Sensing of Environment, 82, pp.303- 310.

- Gitelson, A.; Kaufman, Y. and Merzlyak, M., (1996), Use of a green channel in remote sensing of global vegetation from EOS-MODIS, Remote Sensing of Environment, 58, pp.289- 298.

- Gitelson, A.A; (2004), Wide dynamic range vegetation index for remote quantification of 
- Vermote, E.; Tanre, D.; Deuze, J.; Herman, M. and Morcrette, J., (1977), Second Simulation of the Satellite Signal in the Solar Spectrum, 6s: An Overview, IEEE Transactions on Geoscience and Remote Sensing, 35, 3, pp.675 -686.

- Verrelst, J.; Koetzb, B.; Kneubühlerb, M. and Schaepmana, M., (2006), Directional sensitivity analysis of vegetation indices from multiangular CHRIS/PROBA data, ISPRS Commission VII Mid-term Symposium "Remote Sensing: From Pixels to Processes", 811- May 2006, Enschede, the Netherlands.

- Vincini, M.; Frazzi, E. and D’Alessio, P., (2007), Narrow-band vegetation indexes from hyperion and directional chris/proba data for canopy chlorophyll density estimation in maize, Proc. 'Envisat Symposium 2007', Montreux, Switzerland.

- Wardlow, B.D., Egbert, S.L. and Kastens, J.H., (2007), Analysis of time-series MODIS $250 \mathrm{~m}$ vegetation index data for crop classification in the U.S. Central Great Plains, Remote Sensing of Environment, 108, pp.290-310.

- Wu, J.; Wang, D. and Bauer, M. E., (2007), Assessing broadband vegetation indices and QuickBird data in estimating leaf area index of corn and potato canopies, Field Crops Research, 102, pp. 33- 42 .

- Yang, Z., Willis, P. and Mueller, R., (2008), Impact of band-ratio enhanced a WIFS image to crop classification accuracy, Future of Land Imaging Conference, 18 -20 November. 2008, Denver, Colorado.

- Zhao, D.; Huang, L.; Li, J. and Qi, J., (2007), A comparative analysis of broadband and narrowband derived vegetation indices in predicting LAI and CCD of a cotton canopy, ISPRS Journal of Photogrammetry and Remote Sensing, 62, pp. $25-33$
Didan and Tomoaki, Miura , (2008), Development of a two-band enhanced vegetation index without a blue band, Remote Sensing of Environment, 112 (10), pp.3833 -3845.

- Karnieli, A.; Gabai, A.; Ichoku, C.; Zaady, E. and Shachak, M., (2002), Temporal dynamics of soil and vegetation spectral responses in a semi-arid environment, International Journal of Remote Sensing, 23 (19), pp.4073-4087.

- Kogan, F.; Gitelson, A.; Zakarin, E.; Spivak, L. and Lebed, L., (2003), AVHRR-based spectral vegetation index for quantitative assessment of vegetation state and productivity: calibration and validation, Photogrammetric Engineering and Remote Sensing, 69, 8, pp. 899 -906.

- Pinty, B. and Verstraete, M. M., (1992), GEMI: a non-linear index to monitor global vegetation from satellites, Vegetatio, 101, pp. 15 -20.

- Qi, J.; Chehbouni, A.; Huete, A. R.; Kerr, Y. H. and Sorooshian, S., (1994), A modified soil adjusted vegetation index, Remote Sensing of Environment, 48, pp.119-126.

- Ramachandra, T. V., (2007), Comparative assessment of techniques for bioresource monitoring using gis and remote sensing, The Icfai Journal of Environmental Sciences, 1(2), pp.7- 47.

- Rondeaux, G.; Steven, M. and Baret, F., (1996), Optimization of Soil-Adjusted Vegetation Indices, Remote Sensing of Environment, 55, pp.95- 107.

- Rouse, J. W. Jr., Haas, R., H., Schell, J. A., and Deering, D.W., (1973), Monitoring vegetation systems in the Great Plains with ERTS, Third ERTS Symposium, NASA SP-351 I, pp.309 -317.

- Teillet, P. M.; Staenx, K. and Williams, D. J., (1997), Effects of spectral, spatial, and radiometric characteristics on remote sensing vegetation indices of forested regions, Remote Sensing of Environment, 61, pp.139- 149. 